Check for updates

Cite this: RSC Adv., 2021, 11, 20137

Received 15th April 2021

Accepted 29th May 2021

DOI: $10.1039 / \mathrm{d} 1 \mathrm{ra02938j}$

rsc.li/rsc-advances

\section{Zinc(II) and cadmium(II) amorphous metal-organic frameworks (aMOFs): study of activation process and high-pressure adsorption of greenhouse gases $\dagger$}

\author{
Miroslav Almáši, (D) *a Nikolas Király, ${ }^{a}$ Vladimír Zeleňák, (D) a Mária Vilkováb \\ and Sandrine Bourrelly ${ }^{c}$
}

Two novel amorphous metal-organic frameworks (aMOFs) with chemical composition $\left\{\left[\mathrm{Zn}_{2}(\mathrm{MTA})\right]\right.$. $\left.4 \mathrm{H}_{2} \mathrm{O} \cdot 3 \mathrm{DMF}\right\}_{n}$ (UPJS-13) and $\left\{\left[\mathrm{Cd}_{2}(\mathrm{MTA})\right] \cdot 5 \mathrm{H}_{2} \mathrm{O} \cdot 4 \mathrm{DMF}\right\}_{n}$ (UPJS-14) built from $\mathrm{Zn}(॥)$ and $\mathrm{Cd}(॥)$ ions and extended tetrahedral tetraazo-tetracarboxylic acid $\left(\mathrm{H}_{4} \mathrm{MTA}\right)$ as a linker were prepared and characterised. Nitrogen adsorption measurements were performed on as-synthesized (AS), ethanol exchanged (EX) and freeze-dried (FD) materials at different activation temperatures of $60,80,100,120,150$ and $200{ }^{\circ} \mathrm{C}$ to obtain the best textural properties. The largest surface areas of $830 \mathrm{~m}^{2} \mathrm{~g}^{-1}$ for UPJS-13 (FD) and 1057 $\mathrm{m}^{2} \mathrm{~g}^{-1}$ for UPJS-14 (FD) were calculated from the nitrogen adsorption isotherms for freeze-dried materials activated at mild activation temperature $\left(80^{\circ} \mathrm{C}\right)$. Subsequently, the prepared compounds were tested as adsorbents of greenhouse gases, carbon dioxide and methane, measured at high pressures. The maximal adsorption capacities were $30.01 \mathrm{wt} \% \mathrm{CO}_{2}$ and $4.84 \mathrm{wt} \% \mathrm{CH}_{4}$ for UPJS-13 (FD) and $24.56 \mathrm{wt} \% \mathrm{CO}_{2}$ and $6.38 \mathrm{wt} \% \mathrm{CH}_{4}$ for UPJS-14 (FD) at 20 bar and $30^{\circ} \mathrm{C}$.

\section{Introduction}

Metal-organic frameworks (MOFs) are one of the most exciting classes of porous materials discovered in the past few decades. MOFs are crystalline materials constructed from organic molecules (linkers) coordinated to metal ions or clusters to form interesting polymeric frameworks with a larger surface area and the advantage of pore size changing. Due to the porosity and tunable textural properties, MOF materials find applications in gas storage and separation, ${ }^{1,2}$ heterogeneous catalysis, ${ }^{3,4}$ drug delivery, ${ }^{5,6}$ magnetic refrigeration, ${ }^{7,8}$ sensing, ${ }^{9,10}$ and energy storage. ${ }^{11,12} \mathrm{~A}$ small but growing number of noncrystalline MOFs are steadily capturing scientific interest, though it is only recently that well-characterised examples of amorphous metal-organic frameworks (aMOFs) have started to appear. ${ }^{13-15}$ aMOFs retain the basic building blocks and connectivity of their crystalline counterparts, though they lack any long-range periodic order. aMOFs combine properties that are usually found in crystalline with the unique properties of the amorphous domain such as isotropy, absence of grain

${ }^{a}$ Department of Inorganic Chemistry, Faculty of Science, P. J. Šafárik University, Moyzesova 11, SK-041 54 Košice, Slovak Republic. E-mail: miroslav.almasi@upjs.sk ${ }^{b} N M R$ Laboratory, Faculty of Science, P. J. Šafárik University, Moyzesova 11, SK-041 01 Košice, Slovak Republic

'Aix-Marseille University, CNRS, MADIREL, Marseille Cedex 20, F-133 97, France

$\dagger$ Electronic supplementary information (ESI) available. See DOI: 10.1039/d1ra02938j boundaries, abundant defects and active sites, and flexibility. Most aMOFs have been prepared by applying stress to a crystalline framework. To date, both static and hydrostatic pressures, heating, mechanical stress (ball milling, grinding), radiation, and also chemical treatment have been applied to crystalline MOFs to induce their collapse and amorphization. ${ }^{16}$ However, examples of aMOF materials which have been prepared in the amorphous state by direct synthesis are also known. It should be noted that only a minority number of compounds prepared by the mentioned way are known in the literature: a-UiO-66-SO ${ }_{3} \mathrm{H}\left(S_{\mathrm{BET}}=11 \mathrm{~m}^{2} \mathrm{~g}^{-1}\right),{ }^{17} \mathrm{a}-\mathrm{FMM}-120\left(S_{\mathrm{BET}}\right.$ $\left.=43 \mathrm{~m}^{2} \mathrm{~g}^{-1}\right){ }_{1}^{18}$ CPPs- $X\left(X=1,3,5 ; S_{\mathrm{BET}}=522-588 \mathrm{~m}^{2} \mathrm{~g}^{-1}\right){ }^{19}$ $\operatorname{aZr}-\operatorname{MOF}(X)\left(X=23-26 ; S_{\mathrm{BET}}=410-955 \mathrm{~m}^{2} \mathrm{~g}^{-1}\right),{ }^{20} \mathrm{NEU}-X(X=$ $\left.2-8 ; S_{\mathrm{BET}}=10-294 \mathrm{~m}^{2} \mathrm{~g}^{-1}\right) .{ }^{21-23}$ As was described above, aMOFs have been mostly prepared in a top-down approach by applying stress and introducing disorder into the parent frameworks. In our work we developed bottom-up synthesis of aMOFs, with a high and permanent porosity. Amorphous MOFs offer many exciting opportunities for practical application, either as novel functional materials themselves or facilitating other processes, though the domain is mostly unexplored. ${ }^{24}$ Published articles dealing with aMOFs have been demonstrated to be of potential in several fields, e.g. catalysis, ${ }^{25-28}$ drug delivery, ${ }^{29-33}$ supercapacitors $^{34-36}$ and irreversible harmful substance capture. ${ }^{37,38}$

To study the porosity and textural properties of porous materials is necessary to activate them and thus obtain an open structure. A typical activation process is a thermal activation, in 
which the process of releasing solvent molecules is caused by heat. This activation way often leads to the shrink or collapse of the polymeric frameworks causing a decrease of material's porosity or non-porosity. To reduce the activation temperature, a solvent exchange process is also used as a tool, in which highboiling solvents are exchanged for low-boiling solvents and the thermal activation of porous material occurs at a lower temperature. The freeze-drying process, also known as lyophilisation or cryodesiccation, is a dehydration/desolvation process performed at low temperature, which involves freezing the material with guest molecules and subsequent sublimating the guests under low temperature and low pressure. Lyophilisation is a commercial process preliminary used in biological, biomedical processing, fine food production and preservation. The freeze-drying process has also found an application in the activation of porous materials. ${ }^{39}$ Large specific surface area and better textural properties can be obtained by exchanging of high boiling point solvents $\left(N, N^{\prime}\right.$-dimethylformamide $\left(153{ }^{\circ} \mathrm{C}\right), N, N^{\prime}$ diethylformamide $\left(176{ }^{\circ} \mathrm{C}\right), N, N^{\prime}$-dimethylacetamide $\left(165{ }^{\circ} \mathrm{C}\right)$, dimethylsulfoxide $\left(189^{\circ} \mathrm{C}\right)$ etc. $)$, that are typically located in the pores of as-synthesized material by the solvents with high melting point and high vapour pressure (benzene $\left(5.5{ }^{\circ} \mathrm{C}, 75\right.$ $\mathrm{mmHg}$ at $\left.20{ }^{\circ} \mathrm{C}\right)$, cyclohexane $\left(4{ }^{\circ} \mathrm{C}, 77 \mathrm{mmHg}\right.$ at $\left.20{ }^{\circ} \mathrm{C}\right)$, tertbutyl alcohol $\left(23{ }^{\circ} \mathrm{C}, 31 \mathrm{mmHg}\right.$ at $\left.20{ }^{\circ} \mathrm{C}\right), o$-xylene $\left(-23{ }^{\circ} \mathrm{C}, 7\right.$ $\mathrm{mmHg}$ at $20^{\circ} \mathrm{C}$ ) and compressed $\mathrm{CO}_{2}$ ) followed by evacuation at low temperature. For the organic nature of porous coordination polymers, many MOFs exhibit surface areas that are only a small fraction of predicted/calculated surfaces based on their crystal structures. It was shown that a freeze-drying process could achieve a higher surface area and the desired features of porous materials. For example, freeze-dried compounds $\left[\mathrm{Cu}_{2}(-\right.$ $\left.\mathrm{MTB})\left(\mathrm{H}_{2} \mathrm{O}\right)_{2}\right] \cdot 6 \mathrm{DEF} \cdot 2 \mathrm{H}_{2} \mathrm{O}$ and $\left[\mathrm{Cu}_{2}(\mathrm{MTC})\left(\mathrm{H}_{2} \mathrm{O}\right)_{2}\right]$ $\cdot 14 \mathrm{DMF} \cdot 5 \mathrm{H}_{2} \mathrm{O}$, which also contain tetrahedral linkers $(\mathrm{MTB}=$ methanetetrabenzoate, MTC $=$ methanetetra(biphenyl- $p$ carboxylate)) exhibited surface areas of $526 \mathrm{~m}^{2} \mathrm{~g}^{-1}$ and $791 \mathrm{~m}^{2}$ $\mathrm{g}^{-1}$ for evacuated materials (activation temperature $60{ }^{\circ} \mathrm{C}$ ) and $1560 \mathrm{~m}^{2} \mathrm{~g}^{-1}, 1020 \mathrm{~m}^{2} \mathrm{~g}^{-1}$ for freeze-dried samples, respectively. ${ }^{40}$ As is obvious from described values, lyophilisation is an efficient process for activating porous materials that can increase the surface area three times compared to standard thermal activation.

Global temperature has been rising since the first industrial revolution in the early 19th century, due to the emissions of large quantities of greenhouse gases. The main greenhouse gases are carbon dioxide and methane, but also nitrogen oxides and water vapour. Carbon dioxide is a major by-product of fossil fuel combustion, electricity generation and other anthropogenic activities. Major advances in carbon capture technology could provide power plants and road transport with an efficient and inexpensive way to remove carbon dioxide from their flue gas emissions, which is necessary to reduce greenhouse gas emissions to slow global warming and climate change. The 2030 Climate and Energy Framework commits all EU member states to a $40 \%$ reduction in greenhouse gas emissions over the coming years. ${ }^{41}$ For this reason, it is necessary to develop new and effective carbon dioxide and methane adsorbents as the main greenhouse gases. Many porous materials such as carbon dioxide adsorbents, e.g. MOFs or porous oxides, are modified with nitrogen-containing amine molecules to capture the $\mathrm{CO}_{2}$ (chemisorption) at low-temperature steam to flush out the $\mathrm{CO}_{2}$ for other uses or to sequester it underground are currently being developed and intensively studied. Examples are tetraamineappended MOF $\mathrm{Mg}_{2}$ (dobpdc) (dobpdc $=4,4^{\prime}$-dioxidobiphenyl$3,3^{\prime}$-dicarboxylate, $S_{\mathrm{BET}}=2880 \mathrm{~m}^{2} \mathrm{~g}^{-1}$ ), which can store up $90 \mathrm{wt} \% \mathrm{CO}_{2}$ (ref. 42) and amine grafted silica materials. ${ }^{43-45}$ In order to avoid $\mathrm{CO}_{2}$-intensive energy processes, $\mathrm{CO}_{2}$ molecules must be captured in porous materials by physisorption as a chemisorption process. However, physisorption brings new challenges, because there is a lack of selectivity for $\mathrm{CO}_{2}$ because no chemical bond is formed or when the functional groups are tuned to increase selectivity, the absorption of $\mathrm{CO}_{2}$ is limited.

In the present study, extended tetrahedral nitrogen-rich tetraazo-tetracarboxylic acid $\left(\mathrm{H}_{4} \mathrm{MTA}\right)$ was prepared by sevenstep organic synthesis and used as a linker in the preparation of two novel aMOFs containing $\mathrm{Zn}$ (II) (UPJS-13) and Cd(II) (UPJS14) ions. After characterisation, the textural properties of prepared materials were studied by nitrogen adsorption at $-196{ }^{\circ} \mathrm{C}$ on as-synthesized (AS), ethanol exchanged (EX) and freeze-dried (FD) samples. The specific surface area $\left(S_{\mathrm{BET}}\right)$ depended on the sample pretreatment (AS $<\mathrm{EX}<\mathrm{FD}$ ) and the activation temperature $\left(60-200{ }^{\circ} \mathrm{C}\right)$. The highest $S_{\mathrm{BET}}$ values were obtained for FD materials after activation process at $80{ }^{\circ} \mathrm{C}$ : UPJS-13 (EX) $830 \mathrm{~m}^{2} \mathrm{~g}^{-1}$ and UPJS-14 (EX) $1057 \mathrm{~m}^{2} \mathrm{~g}^{-1}$. After finding the best activation conditions, the materials were tested as adsorbents of greenhouse gases in high-pressure adsorption measurements of carbon dioxide and methane up to 20 bar.

\section{Experimental}

\subsection{Synthetic part}

2.1.1 Used chemicals. All chemicals used in the synthesis of methanetetrayltetrakis(benzene-4,1diyl)tetrakis(aza))tetrakis (methan-1-yl-1-yliden) tetrabenzoic acid, $\mathrm{H}_{4}$ MTA: triphenylmethanol (97\%), aniline (99.5\%), ethyl 4-aminobenzoate (benzocaine, $\geq 98 \%$ ), oxone ( $\geq 99 \%$ ), Pd/C (10\% Pd basis), RANEY ${ }^{\circledR}$ Nickel aluminium alloy (50\% $\mathrm{Al}$ basis, $50 \% \mathrm{Ni}$ basis), hydrazine monohydrate ( $80 \%$ solution in $\mathrm{H}_{2} \mathrm{O}$ ), sodium hydroxide $(90 \%)$, sodium bicarbonate (99.5\%), anhydrous sodium sulphate (99\%), isopentyl nitrite ( $\geq 97 \%)$, hypophosphorus acid (50 wt\% in $\mathrm{H}_{2} \mathrm{O}$ ), ethanol (99.8\%), methanol (extra dry, $\geq 99 \%$ ), glacial acetic acid ( $\geq 99 \%)$, tetrahydrofufan (99\%), dichloromethane (99.5\%), acetic anhydride ( $\geq 98 \%)$, hydrochloric acid $(36 \%)$, fuming acid (99\% $\left.\mathrm{HNO}_{3}\right)$, sulphuric acid (97\%) and amorphous porous materials: zinc(II) nitrate hexahydrate ( $\geq 98 \%$ ), cadmiu$\mathrm{m}(\mathrm{II})$ nitrate tetrahydrate $(98 \%), \quad N, N^{\prime}$-dimethylformamide $(\geq 99 \%)$ were obtained from Sigma-Aldrich, Acros Organics or eMolecules companies, and used without further purification.

2.1.2 Synthesis of $\mathbf{H}_{4}$ MTA. $\mathrm{H}_{4}$ MTA linker was prepared by seven-step organic synthesis according to the reactions presented in Fig. 1 and procedures described below. Reaction conditions were chosen and modified from the literature procedures. ${ }^{46-49}$

2.1.2.1 Synthesis of 4-tritylaniline (1). 4-Tritylaniline was prepared by the condensation reaction of triphenylmethanol 

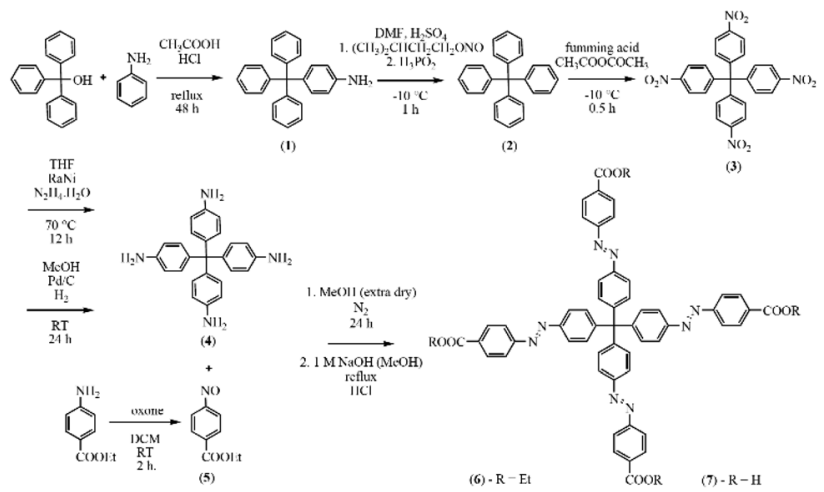

Fig. 1 Synthesis of methanetetrayltetrakis(benzene-4,1-diyl)tetrakis(aza)tetrakis(methan-1-yl-1-yliden)tetrabenzoic acid $\left(\mathrm{H}_{4} \mathrm{MTA}\right)$ with corresponding synthetic conditions.

and aniline. Triphenylmethanol (20 g; $77 \mathrm{mmol})$ was dissolved in glacial acetic acid $\left(230 \mathrm{~cm}^{3}\right)$ and to this solution aniline (11 $\mathrm{cm}^{3} ; 121 \mathrm{mmol}$ ) was added. Finally, the reaction mixture was acidified with concentrated $\mathrm{HCl}\left(38.5 \mathrm{~cm}^{3}\right)$ and refluxed at $130{ }^{\circ} \mathrm{C}$ for $48 \mathrm{~h}$. Subsequently, the reaction mixture was cooled to ambient temperature and diluted in water $\left(1.5 \mathrm{dm}^{3}\right)$. The resulting precipitate of $\mathbf{1}$ was filtered off under reduced pressure using a Buchner funnel. The filter cake was washed several times with water to remove residual acetic and hydrochloric acid. The washed product was placed in an oven and dried at $70{ }^{\circ} \mathrm{C}$ overnight to yield $18.16 \mathrm{~g}$ of 1 (71\% based on triphenylmethanol). ${ }^{1} \mathrm{H}$ NMR (600 MHz, $\left.\mathrm{CDCl}_{3}\right) \delta(\mathrm{ppm}): 5.00(\mathrm{~s}, 2 \mathrm{H})$; $6.46(\mathrm{~d}, 2 \mathrm{H}, J=6.98 \mathrm{~Hz}) ; 6.75$ (d, 2H, $J=6.98 \mathrm{~Hz}) ; 7.09-7.29(\mathrm{~m}$, $15 \mathrm{H})$ ppm. Elemental analysis for $\mathrm{C}_{25} \mathrm{H}_{21} \mathrm{~N}_{1}\left(335.44 \mathrm{~g} \mathrm{~mol}^{-1}\right)$ calculated: C, 89.51\%; H, 6.31\%; N, 4.18\%; measured: C, 89.46\%; H, 6.21\%; N, 4.09. IR (KBr): $\nu(\mathrm{NH}) 3469$ (w), $3382(\mathrm{w})$; $\nu(\mathrm{CH})_{\mathrm{ar} .} 3082(\mathrm{w}), 3054(\mathrm{w}), 3028(\mathrm{w}) ; \delta(\mathrm{NH}) 1621(\mathrm{~m}) ; \nu(\mathrm{C}=\mathrm{C})_{\mathrm{ar}}$. $1593(\mathrm{w}), 1511(\mathrm{w}) ; \delta(\mathrm{CCH})_{\mathrm{ar}} 1183(\mathrm{w}), 1081(\mathrm{w}), 1033(\mathrm{w})$; $\gamma(\mathrm{CCH})_{\mathrm{ar} .} 825(\mathrm{~m}) \mathrm{cm}^{-1}$.

2.1.2.2 Synthesis of tetrakis(phenyl)methane (2). The tetraki$\mathrm{s}$ (phenyl)methane core was prepared by deamination reaction of 4-tritylaniline. 1 (10 g; $30 \mathrm{mmol})$ was dispersed in $N, N^{\prime}$ dimethylformamide (DMF, $125 \mathrm{~cm}^{3}$ ) and the solution was acidified by dropwise addition of concentrated sulphuric acid $\left(62.5 \mathrm{~cm}^{3}\right)$. Sulphuric acid protonated the primary amine of $\mathbf{1}$, causing its complete dissolution in DMF. Subsequently, the reaction mixture was cooled with the solution of ice/sodium chloride to $\approx-10{ }^{\circ} \mathrm{C}$, and then isopentyl nitrite $\left(15 \mathrm{~cm}^{3}\right.$; $112.5 \mathrm{mmol}$ ) was added dropwise. After the addition of isopentyl nitrite, the solution was stirred for $1 \mathrm{~h}$ at $\approx-10{ }^{\circ} \mathrm{C}$. Hypophosphorous acid $\left(30 \mathrm{~cm}^{3} ; 0.5 \mathrm{~mol}\right)$ was added dropwise after the mentioned reaction time, which catalysed the azo bond cleavage of the intermediate. During the addition of $\mathrm{H}_{3} \mathrm{PO}_{2}$, the release of nitrogen was observed and a precipitate of 2 was formed in the mixture. 2 was filtered off under reduced pressure, washed with DMF, methanol and dried in an oven at $70{ }^{\circ} \mathrm{C}$ overnight (yield: $8.83 \mathrm{~g}, 92.4 \%$ based on 1). ${ }^{1} \mathrm{H}$ NMR (600 $\left.\mathrm{MHz} \mathrm{CDCl}_{3}\right) \delta$ (ppm): $7.21(\mathrm{~m}, 20 \mathrm{H}) \mathrm{ppm} .{ }^{13} \mathrm{C}$ NMR $(151 \mathrm{MHz}$, $\left.\mathrm{CDCl}_{3}\right) \delta$ (ppm): 67.0; 125.8; 127.4; 131.1; 146.7 ppm. Elemental analysis for $\mathrm{C}_{25} \mathrm{H}_{20}\left(320.43 \mathrm{~g} \mathrm{~mol}^{-1}\right)$ calculated: $\mathrm{C}, 93.71 \% ; \mathrm{H}$, 6.29\%; measured: C, 92.67\%; H, 6.19\%. IR (KBr): $\nu(\mathrm{CH})_{\text {ar. }} 3080$ (w), $3052(\mathrm{w}), 3029(\mathrm{w}), 3011(\mathrm{w}) ; \nu(\mathrm{C}=\mathrm{C})$ ar. $1591(\mathrm{w}), 1490(\mathrm{~m})$; $\delta(\mathrm{CCH})_{\text {ar. }} 1181(\mathrm{w}), 1080(\mathrm{w}), 1034(\mathrm{w}) ; \gamma(\mathrm{CCH})_{\text {ar. }} 748$ (s), 699 (s) $\mathrm{cm}^{-1}$.

2.1.2.3 Synthesis of tetrakis(p-nitrophenyl)methane (3). Tetrakis( $p$-nitrophenyl)methane was prepared by nitration reaction of 2 using fuming acid. Fuming acid (nitric acid, 99\% $\mathrm{HNO}_{3}$, $12.81 \mathrm{~cm}^{3} ; 0.3 \mathrm{~mol}$ ) was cooled to $\approx-10{ }^{\circ} \mathrm{C}$ using $\mathrm{H}_{2} \mathrm{O} / \mathrm{NaCl}$ bath and $2(2.56 \mathrm{~g} ; 8 \mathrm{mmol})$ was added to the solution in small portions as the reaction is extremely exothermic. After complete addition of 2 , acetic anhydride $\left(4.27 \mathrm{~cm}^{3} ; 45 \mathrm{mmol}\right)$ was added dropwise and the reaction mixture was stirred for $30 \mathrm{~min}$. The last step was a dilution of the reaction mixture into glacial acetic acid $\left(17.1 \mathrm{~cm}^{3}\right)$. A yellow precipitate of 3 was filtered off, washed with acetic acid, methanol and dried in an oven at $50{ }^{\circ} \mathrm{C}$ overnight (yield $1.63 \mathrm{~g}, 40.8 \%$ based on 2 ). Finally, the product was recrystallised from toluene, resulting in a reaction yield of $30 \% .{ }^{1} \mathrm{H}$ NMR (600 MHz, DMSO): $\delta=7.61$ $(8 \mathrm{H}, \mathrm{d}, J=9.01 \mathrm{~Hz}) ; 8.22(8 \mathrm{H}, \mathrm{d}, J=9.01 \mathrm{~Hz}) \mathrm{ppm}$. Elemental analysis for $\mathrm{C}_{25} \mathrm{H}_{16} \mathrm{~N}_{4} \mathrm{O}_{8}\left(500.42 \mathrm{~g} \mathrm{~mol}^{-1}\right)$ calculated: $\mathrm{C}, 60.00 \%$; $\mathrm{H}, 3.22 \%$; N,11.20\%; N, $11.20 \%$; measured C, $60.31 \% ; \mathrm{H}$, $3.18 \%$; N, 11.02\%. IR (KBr): $\nu(\mathrm{CH})$ ar. $3109(\mathrm{w}), 3079(\mathrm{w}) ; \nu(\mathrm{C}=$ C) ar. $1604(\mathrm{~m}), 1589(\mathrm{~m}), 1493(\mathrm{w})$; $\nu_{\text {as. }}\left(\mathrm{C}-\mathrm{NO}_{2}\right) 1520(\mathrm{~s}) ; \nu_{\mathrm{s} .}(\mathrm{C}-$ $\left.\mathrm{NO}_{2}\right) 1337(\mathrm{~s}) ; \delta(\mathrm{CCH})$ ar. $1106(\mathrm{~m}), 1009(\mathrm{w}) ; \gamma(\mathrm{CCH})$ ar. $837(\mathrm{~s})$, $743(\mathrm{~s}) \mathrm{cm}^{-1}$.

2.1.2.4 Preparation of tetrakis(p-aminophenyl)methane (4). The aim of this synthetic step was the reduction reaction of nitro to an amino group. The reduction was carried out by two synthetic procedures using different catalysts and reducing agents: hydrazine/RaNi or $\mathrm{Pd} / \mathrm{C}$ and hydrogen, respectively.

2.1.2.4.1 Synthesis using hydrazine/RaNi. The reaction mixture of 3 ( $0.3 \mathrm{~g} ; 0.9 \mathrm{mmol})$, hydrazine monohydrate $\left(\mathrm{N}_{2} \mathrm{H}_{4} \cdot \mathrm{H}_{2} \mathrm{O} ; 0.4 \mathrm{~g} ; 8 \mathrm{mmol} ; 50 \%\right.$ aqueous solution $)$ and $\mathrm{RANEY}^{\circledR}$ nickel $(\mathrm{Ra} / \mathrm{Ni} ; 10 \mathrm{~g})$ in THF $\left(50 \mathrm{~cm}^{3}\right)$ was refluxed for 12 hours. The reaction mixture was hot filtered under reduced pressure to remove the heterogeneous catalyst and washed with THF. The filtered solution was evaporated under vacuum until the first visible crystals of the product were formed. The crystallised product $\mathbf{4}$ was filtered off, slightly washed with ethanol and finally purified from hot ethyl acetate (yield: $0.18 \mathrm{~g}, 78 \%$ based on 3$)$.

2.1.2.4.2 Synthesis using $P d / C$ and hydrogen. 3 (0.5 g; 0.99 $\mathrm{mmol})$ was dissolved in methanol $\left(20 \mathrm{~cm}^{3}\right)$ and heterogeneous $\mathrm{Pd} / \mathrm{C}$ catalyst $(0.1 \mathrm{~g} ; 0.05 \mathrm{mmol})$ was added to the solution in small portions. The reaction mixture was stirred vigorously and the hydrogen atmosphere was created as follows: the pressure in the system was reduced by a vacuum pump until boiling of the methanol occurred and hydrogen was introduced into the system. This procedure was repeated four times. Subsequently, the reaction mixture was stirred for $24 \mathrm{~h}$ in a reducing atmosphere of hydrogen at room temperature. The product was filtered off, washed with methanol and dried under vacuum. 4 was purified by column chromatography on silica gel using a solvent mixture of DCM : $\mathrm{MeOH}(7: 1, \mathrm{v} / \mathrm{v})$ as mobile phase (yield: $0.27 \mathrm{~g}, 71 \%$ based on 3 ). 
2.1.2.4.3 ${ }^{1} \mathrm{H} N M R(600 \mathrm{MHz}, \mathrm{DMSO}) \delta(\mathrm{ppm}) .4 .84(4 \mathrm{H}, \mathrm{s})$; $6.39(8 \mathrm{H}, \mathrm{d}, J=8.4 \mathrm{~Hz}) ; 6.67(8 \mathrm{H}, \mathrm{d}, J=8.4 \mathrm{~Hz})$. Elemental analysis for $\mathrm{C}_{25} \mathrm{H}_{24} \mathrm{~N}_{4}\left(380.48 \mathrm{~g} \mathrm{~mol}^{-1}\right)$ calculated: $\mathrm{C}, 78.92 \% ; \mathrm{H}$, 6.36\%; N, 14.73\%; measured: C, 79.13\%; H, 6.28\%; N, 14.49\%. IR (KBr): $\nu\left(\mathrm{NH}_{2}\right) 3465(\mathrm{~m}), 3382(\mathrm{~m}) ; \nu(\mathrm{CH})_{\text {ar. }} 3082(\mathrm{w}), 3054(\mathrm{w})$, $3027(\mathrm{w}) ; \nu(\mathrm{C}=\mathrm{C})$ ar. $1505(\mathrm{~s}), 1593(\mathrm{~m}) ; \delta\left(\mathrm{NH}_{2}\right) 1621(\mathrm{~m}) ; \nu(\mathrm{C}-\mathrm{N})$ $1286(\mathrm{~s}) ; \delta(\mathrm{CCH})_{\text {ar. }} 1182(\mathrm{~m}), 1115(\mathrm{~m}), 1033(\mathrm{w}) ; \gamma(\mathrm{CCH})_{\text {ar. }} 825$ (w), $749(\mathrm{~m}), 701(\mathrm{~s}) \mathrm{cm}^{-1}$.

2.1.2.5 Preparation of ethyl 4-nitrosobenzoate (5). $2.5 \mathrm{~g}$ (15 $\mathrm{mmol}$ ) of ethyl 4-aminobenzoate was dissolved in $50 \mathrm{~cm}^{3}$ of dichloromethane (DCM) and solution of oxone (potassium peroxymonosulfate, $\left.\mathrm{KHSO}_{5} \cdot 0.5 \mathrm{KHSO}_{4} \cdot 0.5 \mathrm{~K}_{2} \mathrm{SO}_{4}\right) 20.3 \mathrm{~g}(66 \mathrm{mmol})$ in $200 \mathrm{~cm}^{3}$ of deionised water was added. The reaction mixture was stirred at room temperature for $2 \mathrm{~h}$. After the colour change from colourless to green, the mixture was extracted with $\mathrm{CH}_{2} \mathrm{Cl}_{2}$ and washed with $\mathrm{H}_{2} \mathrm{O}$ several times. The organic layer was further washed with $30 \mathrm{~cm}^{3}$ of $1 \mathrm{M} \mathrm{HCl}$ and $40 \mathrm{~cm}^{3}$ of $\mathrm{NaHCO}_{3}$ saturated aqueous solution. The suspension was extracted with $\mathrm{CH}_{2} \mathrm{Cl}_{2}(4$ $\times 50 \mathrm{~cm}^{3}$ ) and dried with $\mathrm{Na}_{2} \mathrm{SO}_{4}$. The organic layers were collected and the solvent was removed under reduced pressure to form the light-yellow product of 5 (yield $2.03 \mathrm{~g}, 75 \%$ based on ethyl 4-aminobenzoate). ${ }^{1} \mathrm{H}$ NMR (600 MHz, $\left.\mathrm{CDCl}_{3}\right) \delta(\mathrm{ppm}): 1.24$ $(3 \mathrm{H}, \mathrm{t}, J=7.1 \mathrm{~Hz}), 4.14(2 \mathrm{H}, \mathrm{q}, J=7.1 \mathrm{~Hz}), 8.07(2 \mathrm{H}, \mathrm{ddd}, J=8.5$, 1.6, $0.5 \mathrm{~Hz}), 8.13(2 \mathrm{H}$, ddd, $J=8.5,1.4,0.5 \mathrm{~Hz})$. Elemental analysis for $\mathrm{C}_{9} \mathrm{H}_{9} \mathrm{NO}_{3}\left(179.17 \mathrm{~g} \mathrm{~mol}^{-1}\right)$ calculated: $\mathrm{C}, 60.33 \% ; \mathrm{H}, 5.06 \% ; \mathrm{N}$, 7.82\%; measured: C, 60.54\%; H, 4.99\%; N, 7.89\%. IR ( $\mathrm{KBr})$ : $\nu(\mathrm{CH})_{\text {ar. }} 3103(\mathrm{w}), 3072(\mathrm{w}), 3050(\mathrm{w}) ; \nu(\mathrm{CH})_{\text {aliph. }} 2864(\mathrm{w}), 2901(\mathrm{w})$, $2932(\mathrm{w}), 2979(\mathrm{w}) ; \nu(\mathrm{C}=\mathrm{O}) 1703(\mathrm{~s}) ; \nu(\mathrm{C}-\mathrm{N}) 1529(\mathrm{w}) ; \gamma(\mathrm{CCH})_{\text {ar. }}$ 874 (s), 689 (s) $\mathrm{cm}^{-1}$.

2.1.2.6 Preparation of methanetetrayltetrakis(benzene-4,1diyl)tetrakis(aza))tetrakis (methan-1-yl-1-yliden)tetrabenzoic acid ethyl ester ( $\left.E t_{4} M T A\right)$ (6). $\mathrm{Et}_{4} \mathrm{MTA}$ was prepared by the condensation reaction of ethyl 4-nitrosobenzoate and tetrakis ( $p$-aminophenyl)methane. Solution of $5(1.6 \mathrm{~g}, 9 \mathrm{mmol})$ in $40 \mathrm{~cm}^{3}$ of acetic acid was added dropwise during $10 \mathrm{~min}$ time period in solution of $4(0.7 \mathrm{~g}, 1.8 \mathrm{mmol})$ dissolved in $40 \mathrm{~cm}^{3}$ of glacial acetic acid and $50 \mathrm{~cm}^{3}$ of extra dry methanol under nitrogen. The reaction mixture was stirred at laboratory temperature in an inert atmosphere of nitrogen for 2 days. Formed orange suspension of $\mathbf{6}$ was filtered off, washed with saturated aqueous solution of $\mathrm{NaHCO}_{3}$, water and methanol $\left(3 \times 15 \mathrm{~cm}^{3}\right)$ and dried at $60{ }^{\circ} \mathrm{C}$ in an oven overnight (yield: $1.21 \mathrm{~g}, 64 \%$ based on 4). ${ }^{1} \mathrm{H}$ NMR (600 MHz, $\left.\mathrm{CDCl}_{3}\right) \delta(\mathrm{ppm}): 8.19(8 \mathrm{H}, \mathrm{d}, J=8.9, \mathrm{H}-$ $\left.3^{\prime \prime}, 5^{\prime \prime}\right), 7.94\left(8 \mathrm{H}, \mathrm{d}, J=8.9, \mathrm{H}-2^{\prime \prime}, 6^{\prime \prime}\right), 7.92\left(8 \mathrm{H}, \mathrm{d}, J=8.8, \mathrm{H}-3^{\prime}, 5^{\prime}\right)$, $7.54\left(8 \mathrm{H}, \mathrm{d}, J=8.8, \mathrm{H}-2^{\prime}, 6^{\prime}\right), 4.42(8 \mathrm{H}, \mathrm{q}, J=7.1, \mathrm{H}-5), 1.43(12 \mathrm{H}$, $\mathrm{t}, J=7.1, \mathrm{H}-6) ;{ }^{13} \mathrm{C}$ NMR $\left(151 \mathrm{MHz}, \mathrm{CDCl}_{3}\right) \delta(\mathrm{ppm}): 166.1(\mathrm{C}-4)$, $155.2\left(\mathrm{C}-1^{\prime \prime}\right), 151.0\left(\mathrm{C}-4^{\prime}\right), 149.3\left(\mathrm{C}-1^{\prime}\right), 132.5\left(\mathrm{C}-4^{\prime \prime}\right), 131.8(\mathrm{C}-$ $\left.2^{\prime}, 6^{\prime}\right), 130.7\left(\mathrm{C}-3^{\prime \prime}, 5^{\prime \prime}\right), 122.9\left(\mathrm{C}-3^{\prime}, 5^{\prime}\right), 122.8\left(\mathrm{C}-2^{\prime \prime}, 6^{\prime \prime}\right), 65.6(\mathrm{C}-1)$, 61.4 (C-5), 14.5 (C-6). Elemental analysis for $\mathrm{C}_{61} \mathrm{H}_{52} \mathrm{~N}_{8} \mathrm{O}_{8}$ (1025.11 $\mathrm{g} \mathrm{mol}^{-1}$ ) calculated: C, 71.47\%; H, 5.11\%; N, 10.93\%; measured: C, 71.37\%; H, 5.03\%; N, 11.18\%. IR (KBr): $\nu(\mathrm{C}=\mathrm{O})$ $1679(\mathrm{~s}) ; \nu(\mathrm{C}=\mathrm{C})_{\text {ar. }} 1599(\mathrm{w}) ; \nu(\mathrm{N}=\mathrm{N}) 1494(\mathrm{w}) ; \delta(\mathrm{CCH})$ ar. 1085 (m), $1009(\mathrm{~m}) ; \gamma(\mathrm{CCH})$ ar. $868(\mathrm{~m}), 699(\mathrm{~s}) \mathrm{cm}^{-1}$. Assignments of hydrogen and carbon atoms are depicted in Fig. $\mathrm{S} 1$ in $\mathrm{ESI} \dagger$ and 2D NMR experiments: ${ }^{1} \mathrm{H},{ }^{1} \mathrm{H}-\mathrm{COSY} ;{ }^{1} \mathrm{H},{ }^{13} \mathrm{C}-\mathrm{HSQC} ;{ }^{1} \mathrm{H},{ }^{13} \mathrm{C}$ HMBC spectra of 6 are presented in Fig. S2-S4 in ESI. $\dagger$
2.1.2.7 Preparation of methanetetrayltetrakis(benzene-4,1diyl)tetrakis(aza))tetrakis(methan-1-yl-1-yliden)tetrabenzoic acid ( $\mathrm{H}_{4} \mathrm{MTA}$ ) (7). The last synthesis step in $\mathrm{H}_{4}$ MTA preparation was deesterification reaction of its ethyl ester (6). 6 (270 mg, 0.26 $\mathrm{mmol}$ ) was suspended and stirred in $150 \mathrm{~cm}^{3}$ solution of $1 \mathrm{M}$ $\mathrm{NaOH}$ in methanol and heated at $80{ }^{\circ} \mathrm{C}$ for $2 \mathrm{~h}$. After this time the reaction mixture was cooled down to ambient temperature, filtrated and the solvent was removed under vacuum. The crude product was dissolved in water and solution was subsequently acidified with concentrated $\mathrm{HCl}$ until $\mathrm{pH}=1$. Orange solid of 7 was precipitated, filtered off, washed with water and dried in an over at $50{ }^{\circ} \mathrm{C}$ overnight (yield: $226 \mathrm{mg}, 94 \%$ based on 6 ). ${ }^{1} \mathrm{H}$ NMR (600 MHz, DMSO-d $\left.{ }_{6}\right) \delta(\mathrm{ppm}): 13.25(4 \mathrm{H}, \mathrm{s}, \mathrm{OH}), 8.14(8 \mathrm{H}, \mathrm{d}, J=$ $\left.8.5, \mathrm{H}-3^{\prime \prime}, 5^{\prime \prime}\right), 7.95\left(8 \mathrm{H}, \mathrm{d}, J=8.5, \mathrm{H}-2^{\prime \prime}, 6^{\prime \prime}\right), 7.96(8 \mathrm{H}, \mathrm{d}, J=8.8, \mathrm{H}-$ $\left.3^{\prime}, 5^{\prime}\right), 7.60\left(8 \mathrm{H}, \mathrm{d}, J=8.5, \mathrm{H}-2^{\prime}, 6^{\prime}\right) .{ }^{13} \mathrm{C}$ NMR (151 MHz, DMSO$\left.\mathrm{d}_{6}\right) \delta(\mathrm{ppm}): 166.6(\mathrm{C}-4), 154.4\left(\mathrm{C}-1^{\prime \prime}\right), 150.1\left(\mathrm{C}-4^{\prime}\right), 149.2\left(\mathrm{C}-1^{\prime}\right)$, $132.9\left(\mathrm{C}-4^{\prime \prime}\right), 131.5\left(\mathrm{C}-2^{\prime}, 6^{\prime}\right), 130.7\left(\mathrm{C}-3^{\prime \prime}, 5^{\prime \prime}\right), 122.8\left(\mathrm{C}-3^{\prime}, 5^{\prime}\right), 122.5$ $\left(\mathrm{C}-2^{\prime \prime}, 6^{\prime \prime}\right), 65.2$ (C-1). Elemental analysis for $\mathrm{C}_{53} \mathrm{H}_{36} \mathrm{~N}_{8} \mathrm{O}_{8}(912.9 \mathrm{~g}$ $\mathrm{mol}^{-1}$ ) calculated: $\mathrm{C}, 69.73 \%$;, $3.97 \% ; \mathrm{N}, 12.27 \%$; measured: C, 69.35\%; H, 4.08\%; N, 12.18\%. IR (KBr): $\nu(\mathrm{OH})_{\text {ar. }} 3420(\mathrm{w}, \mathrm{br})$; $\nu(\mathrm{CH})_{\text {ar. }} 3106(\mathrm{w}), 3069(\mathrm{w}) ; \nu(\mathrm{CH})_{\text {aliph. }} 2982(\mathrm{w}), 2960(\mathrm{w}), 2929$ $(\mathrm{w}) ; \nu(\mathrm{C}=\mathrm{O}) 1709(\mathrm{~s}) ; \nu(\mathrm{C}=\mathrm{C})$ ar. $1597(\mathrm{w}) ; \nu(\mathrm{N}=\mathrm{N}) 1521(\mathrm{w})$; $\delta(\mathrm{CCH})_{\text {ar. }} 1085(\mathrm{~m}), 1009(\mathrm{~m}) ; \gamma(\mathrm{CCH})_{\text {ar. }} 858(\mathrm{~m}), 697(\mathrm{~s}) \mathrm{cm}^{-1}$. 2D NMR experiments: ${ }^{1} \mathrm{H},{ }^{13} \mathrm{C}-\mathrm{HSQC}$ and ${ }^{1} \mathrm{H},{ }^{13} \mathrm{C}-\mathrm{HMBC}$ spectra of 7 are presented in Fig. S5 and S6 in ESI. $\dagger$

2.1.3 Synthesis of UPJS-13 and UPJS-14. A mixture of $\mathrm{H}_{4}$ MTA (10 mg, $\left.0.011 \mathrm{mmol}\right)$ and $\mathrm{Cd}\left(\mathrm{NO}_{3}\right)_{2} \cdot 4 \mathrm{H}_{2} \mathrm{O}(27 \mathrm{mg}, 0.088$ $\mathrm{mmol})$ or $\mathrm{Zn}\left(\mathrm{NO}_{3}\right)_{2} \cdot 6 \mathrm{H}_{2} \mathrm{O}(6.5 \mathrm{mg}, 0.022 \mathrm{mmol})$ were dissolved in a solvent mixture of $\mathrm{DMF} / \mathrm{H}_{2} \mathrm{O}\left(6 \mathrm{~cm}^{3} / 0.5 \mathrm{~cm}^{3}\right)$ in a screwcapped vial. The vial was capped and placed in an oven and reaction mixtures were heated at $80{ }^{\circ} \mathrm{C}$ for five days. Prepared orange crystals (see Fig. 2) of materials were filtered off, slightly washed with ethanol and dried in the stream of air (yield: $12.4 \mathrm{mg}, \mathbf{8 5} \%$ for UPJS-13 (AS) and $14.8 \mathrm{mg}, \mathbf{8 9} \%$ for UPJS-14 (AS) based on $\mathrm{H}_{4}$ MTA). UPJS-13 (AS), $\left\{\left[\mathrm{Zn}_{2}(\mathrm{MTA})\right] \cdot 4 \mathrm{H}_{2}\right.$ $\mathrm{O} \cdot 3 \mathrm{DMF}\}_{n}, M_{\mathrm{r}}=1331.00 \mathrm{~g} \mathrm{~mol} \mathrm{~m}^{-1}, \mathrm{CHN}$ and AAS: clcd: C $55.95 \%, \mathrm{H}$ 4.62\%, N 11.58\%, Zn 9.83\%; exp.: C 55.84\%, H 4.66\%, N 11.69\%, Zn 9.95\%; UPJS-14 (AS), $\left\{\left[\mathrm{Cd}_{2}(\mathrm{MTA})\right] \cdot 5 \mathrm{H}_{2}-\right.$ $\mathrm{O} \cdot 4 \mathrm{DMF}\}_{n}, M_{\mathrm{r}}=1516.15 \mathrm{~g} \mathrm{~mol}{ }^{-1}, \mathrm{CHN}$ and AAS: clcd.: $\mathrm{C}$ $51.49 \%, \mathrm{H}$ 4.65\%, N 11.09\%, Cd 14.83\%; exp.: C $51.44 \%, \mathrm{H}$ $4.61 \%$, N $11.17 \%$, Cd $14.76 \%$.

\subsubsection{Preparation of the samples for gas adsorption} measurements

2.1.4.1 As-synthesized samples (AS). The as-synthesized samples for nitrogen adsorption experiments were prepared by repeating the synthetic procedure described in Section 2.1.3 Synthesis of UPJS-13 and UPJS-14. After collecting of sufficient amount of the sample, the material was stored in the mother liquor. The collected material was further activated under vacuum at selected temperatures described in Section 2.2.6 Nitrogen adsorption measurements.

2.1.4.2 Ethanol exchanged samples (EX). The ethanol exchanged samples were prepared by immersing of the assynthesized materials in ethanol for 14 days, while ethanol was changed every day. Ethanol exchanged samples were 

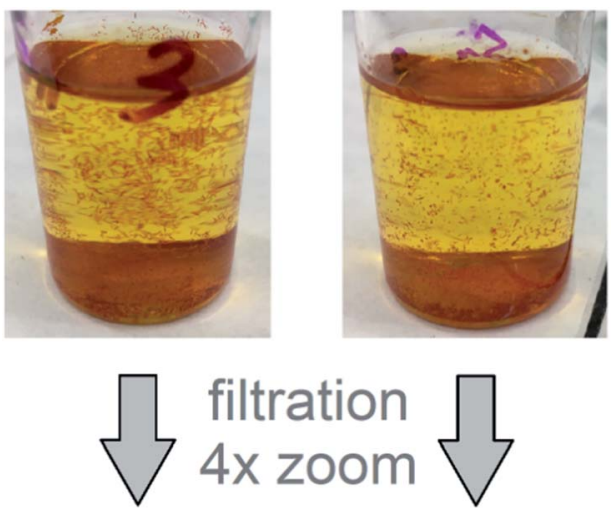

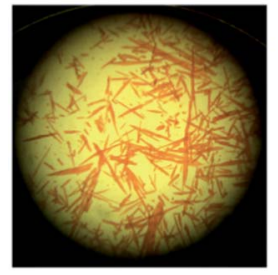

a)

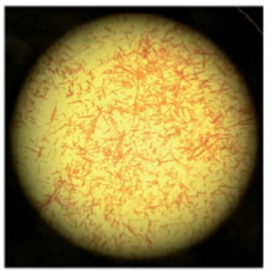

b)
Fig. 2 Prepared orange quasi-crystals of (a) UPJS-13 (AS) and (b) UPJS-14 (AS) in screwcapped vials and after filtration process and $4 \times$ zoom.

activated under vacuum at selected temperatures described in Section 2.2.6 Nitrogen adsorption measurements.

2.1.4.3 Freeze-dried samples (FD). The freeze-dried samples were prepared by immersing the as-synthesized materials in benzene for 14 days, while benzene was changed every day. Subsequently, the suspension of the sample in benzene was frozen at $-20{ }^{\circ} \mathrm{C}$. After five freeze-thaw cycles, the benzene exchanged material in sample cells were placed under vacuum using a turbomolecular pump at $-20{ }^{\circ} \mathrm{C}$ for $24 \mathrm{~h}$, and further heated under vacuum at selected temperatures described in Section 2.2.6 Nitrogen adsorption measurements. Schematic representation of the described freeze-drying process is shown in Fig. 3.

\subsection{Methods and characterisation}

2.2.1 Elemental analysis and ICP-MS. The elemental analysis was performed using a CHNOS Elemental Analyzer Vario

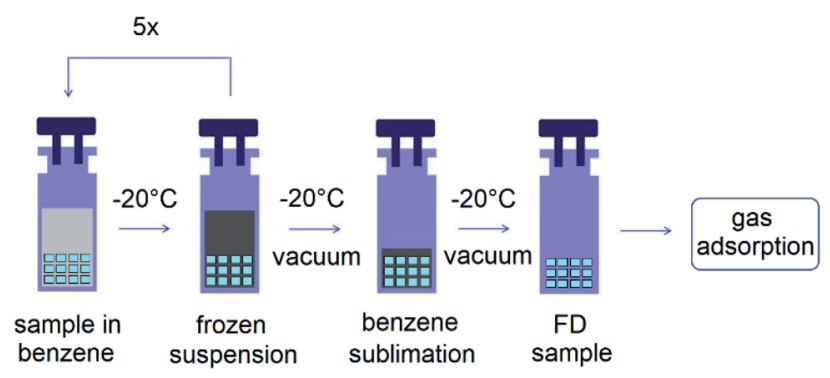

Fig. 3 Scheme of the freeze-drying process.
MICRO from Elementar Analysensysteme $\mathrm{GmbH}$ with a sample weight of approximately $3 \mathrm{mg}$. The determination of metal ions amount in as-synthesized aMOFs was carried out on the ICP-MS 7700 instrument developed by Agilent Technologies, in the atmosphere of argon. Before measurements, the samples were mineralised in hot aqua regia.

2.2.2 Infrared spectroscopy. The infrared spectra of the samples were measured at ambient temperature and recorded using an Avatar FTIR 6700 spectrometer in the wavenumber range of $4000-400 \mathrm{~cm}^{-1}$ with 64 repetitions for a single spectrum. Materials were measured using $\mathrm{KBr}$ technique in mass ratio $1: 100$ (sample: $\mathrm{KBr}$ ). Potassium bromide was before measurements dried in an oven at $500{ }^{\circ} \mathrm{C}$ for $4 \mathrm{~h}$ and cooled in a desiccator.

2.2.3 NMR spectroscopy. Nuclear magnetic resonance data were collected on a Varian VNMRS 600 spectrometer operating at $599.87 \mathrm{MHz}$ for ${ }^{1} \mathrm{H}$ and $150.84 \mathrm{MHz}$ for ${ }^{13} \mathrm{C}$. The mass concentration of all samples was approximately $10 \mathrm{mg} / 0.6 \mathrm{~mL}$ of DMSO- $\mathrm{d}_{6}$ or $\mathrm{CDCl}_{3}$, and the chemical shifts were referenced to the residual solvent peak $\left({ }^{1} \mathrm{H}\right.$ NMR $2.50 \mathrm{ppm}$ and ${ }^{13} \mathrm{C}$ NMR $39.5 \mathrm{ppm}$ for DMSO- $\mathrm{d}_{6} ;{ }^{1} \mathrm{H}$ NMR $7.26 \mathrm{ppm}$ and ${ }^{13} \mathrm{C}$ NMR $77.0 \mathrm{ppm}$ for $\mathrm{CDCl}_{3}$ ). The NMR data were recorded at $300 \mathrm{~K}$, with chemical shifts $(\delta)$ reported in parts per million and coupling constants $(J)$ in Hertz. The 2D experiments gCOSY, gHSQC and gHMBC were run using the standard Varian software. All data were analysed using MNova 7.1.1 (2012) software. The spectral acquisition parameters are summarised in Section 2.1.2 Synthesis of $\mathrm{H}_{4} \mathrm{MTA}$ and selected spectra are shown in Fig. 4 and S1-S7 in ESI. $\dagger$
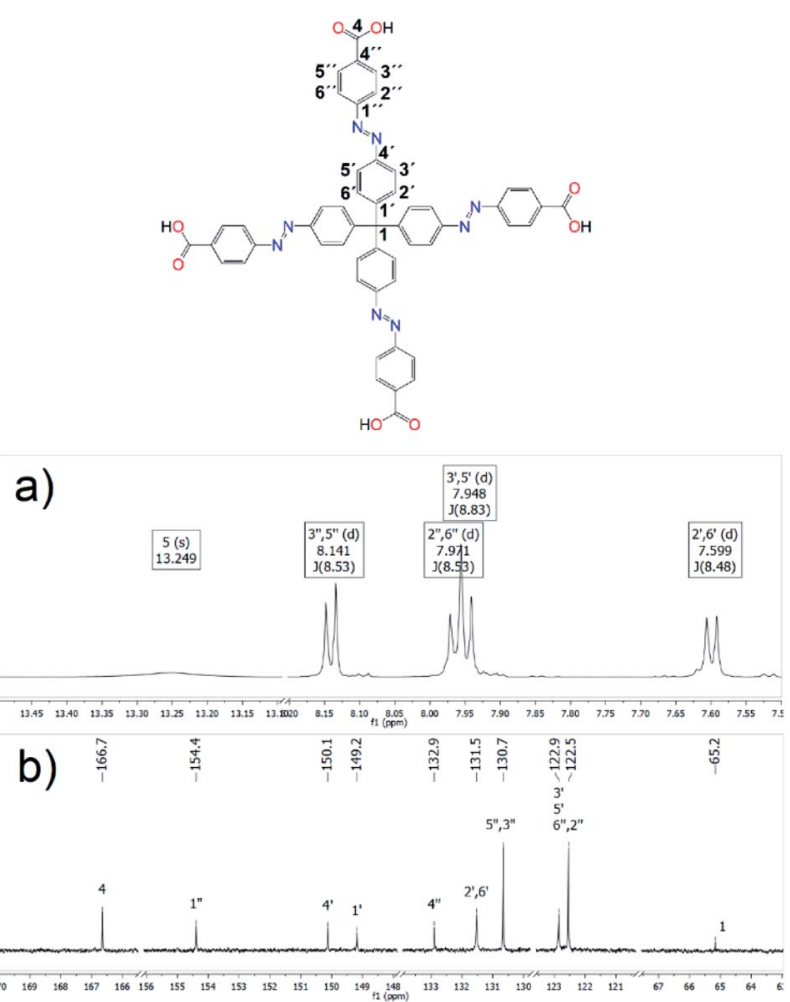

Fig. 4 (a) ${ }^{1} \mathrm{H}(600 \mathrm{MHz})$ and (b) ${ }^{13} \mathrm{C}(151 \mathrm{MHz})$ NMR spectra of $\mathrm{H}_{4} \mathrm{MTA}$ in $\mathrm{DMSO}-\mathrm{d}_{6}$ with assignments of hydrogen and carbon atoms. 
2.2.4 Solid-state NMR spectroscopy. The solid-state NMR measurements of $\mathrm{H}_{4}$ MTA and activated compounds, UPJS-13 and UPJS-14, were carried out on a Bruker Advance III HD WB/ US NMR spectrometer at a temperature of $30{ }^{\circ} \mathrm{C}$ in a $4 \mathrm{~mm}$ probehead at a spinning frequency of $10 \mathrm{kHz}$ (magnetic field strength 11.7T). In all cases powdered and dried samples were placed into zirconium(Iv) oxide rotors with $4 \mathrm{~mm}$ size. ${ }^{13} \mathrm{C}$ MAS NMR spectra ( $\mathrm{T}_{1}$ filtered) of compounds were recorded using the single pulse experiment with a high power dipolar decoupling and a $2 \times 10^{3}$ number of scans. A standard crosspolarization pulse (contact time $\sim 1 \mathrm{~ms}$ ) sequence was used to measure ${ }^{13} \mathrm{C} \mathrm{CP} / \mathrm{MAS} \mathrm{NMR}$ spectra. The applied nutation frequency of $\mathrm{B}_{1}\left({ }^{1} \mathrm{H}\right)$ and $\mathrm{B}_{1}\left({ }^{13} \mathrm{C}\right)$ fields during the crosspolarization period was $62.5 \mathrm{kHz}$ and the repetition delay was 2-4 s. Glycine was used as an external standard (176.03 ppm $(\mathrm{C}=\mathrm{O})$ ) for calibration of ${ }^{13} \mathrm{C}$ NMR scale.

2.2.5 Thermal analysis. The thermal behaviour of prepared samples was studied by thermogravimetric analysis (TGA) with a sample weight of approximately $10 \mathrm{mg}$, using platinum crucibles. Samples were heated in the temperature range of 30$800{ }^{\circ} \mathrm{C}$ with a heating rate of $10{ }^{\circ} \mathrm{C} \cdot \mathrm{min}^{-1}$ in a dynamic air atmosphere with a flow rate of $50 \mathrm{~cm}^{3} \mathrm{~min}^{-1}$, using TGA Q600 apparatus.

2.2.6 X-ray diffraction experiments. Single-crystal diffraction analysis were collected on a Bruker D8 VENTURE Kappa Duo PHOTON 100 diffractometer using MoK $\alpha$ radiation $(\lambda=$ $0.71073 \AA$ ). The sample crystals were cooled to $-150^{\circ} \mathrm{C}$ by using an Oxford Cryostream cooler. Experimental data were processed by the diffractometer software. Powder X-ray diffraction (PXRD) experiments were done in reflection geometry using a Bruker D8 ADVANCE ECO multipurpose diffractometer. In order to achieve a parallel and clean X-ray beam for PXRD experiments, initially divergent $\mathrm{Cu}-\mathrm{K} \alpha$ radiation $(\lambda=1.54056 \AA)$ emitted from copper X-ray lamp was further guided through the multi-layered mirror and set of slits. Powder samples were loaded in a glass frame and PXRD experiments were done by $2 \theta$ continuous scan at $0.5^{\circ} \mathrm{min}^{-1}$ from $10^{\circ}$ to $100^{\circ}$ so that scattered photons were recorded every $0.02^{\circ}$ using a $\mathrm{NaI}$ scintillation detector at ambient temperature.

2.2.7 Gas adsorption measurements. Nitrogen adsorption isotherms were taken using a Quantachrome Nova 1200e apparatus at $-196^{\circ} \mathrm{C}$. Prior to nitrogen adsorption, the samples were outgassed at different temperatures $(60,80,100,120,150$ and $200{ }^{\circ} \mathrm{C}$ ) for $12 \mathrm{~h}$ under the vacuum to remove solvent molecules from the pores. The adsorption isotherms of desolvated samples were collected in a relative pressure range from $p / p_{0}=0.005$ to 0.95 . Based on the nitrogen adsorption measurements, the BET specific surface area $\left(S_{\mathrm{BET}}\right)$ of each sample was evaluated using adsorption data in a $p / p_{0}$ range from 0.05 to 0.20 .

The gas adsorption measurements at $30{ }^{\circ} \mathrm{C}$ and pressures up to 20 bar were made with carbon dioxide and methane using a homemade high-throughput instrument. ${ }^{50}$ Gas adsorption was measured via a manometric gas dosing system on both samples in parallel. The amounts of gas adsorbed were calculated by an equation of state using the Reference Fluid
Thermodynamic and Transport Properties (REFPROP) software package 8.0 of the National Institute of Standards and Technology (NIST) ${ }^{51}$ Approximately $100 \mathrm{mg}$ of sample was used, and the sample was thermally activated individually in situ under a primary vacuum, at a given final temperature overnight. Methane was of $99.9995 \%$ purity (N55), carbon dioxide was of 99.995\% purity (N45) and gases were obtained from Air Liquide. The weight of the samples used in the high-pressure adsorption experiments was approximately $100 \mathrm{mg}$ and before measurements, the freeze-dried samples were activated at $80{ }^{\circ} \mathrm{C}$ under vacuum for $12 \mathrm{~h}$.

\section{Results and discussion}

\subsection{Synthesis and NMR spectroscopy}

The $\mathrm{H}_{4}$ MTA ligand used in the preparation of aMOFs in the present study was synthesized by the seven-step organic synthesis (see Fig. 1). First, a tetraphenylmethane core was synthesized by the condensation reaction of triphenylmethanol and aniline and the prepared product was subsequently deaminated. Further reactions led to the introduction of nitro groups using fuming acid, which were subsequently reduced to amine groups. Described reactions led to the preparation of the first essential component required for the construction of $\mathrm{H}_{4}$ MTA. The second basic component, ethyl 4-nitrosobenzoate, was prepared by transforming the nitro group to the nitroso group using oxone. The resulting $\mathrm{H}_{4} \mathrm{MTA}$ acid was prepared by the condensation reaction of ethyl 4-nitrosobenzoate with tetrakis-( $p$-aminophenyl)methane in anhydrous methanol and prepared ethyl ester was further deesterified in a concentrated solution of sodium hydroxide in methanol, followed by acidifying the solution to $\mathrm{pH}=1$.

NMR spectroscopy was used for molecular structure determination of all prepared organic compounds (see 2.1.2 Synthesis of $\mathrm{H}_{4} \mathrm{MTA}$ ). The procedure to assign the NMR data of derivative 6 is described as an example. Compound 6 consists of twelve carbons. The carbonyl carbon is easily detectable in ${ }^{13} \mathrm{C}$ NMR spectrum because of the chemical shift $166.2 \mathrm{ppm}$. The carbon peak at $166.2 \mathrm{ppm}$ showed long-range couplings to signals of proton at $4.42 \mathrm{ppm}(\mathrm{q}, J=7.1 \mathrm{~Hz}$ ), protons at $8.19 \mathrm{ppm}(\mathrm{d}, J=8.8 \mathrm{~Hz})$ and protons at $7.94 \mathrm{ppm}(\mathrm{d}, J=8.8 \mathrm{~Hz})$. The proton signal at $4.42 \mathrm{ppm}$ was easily assigned as $\mathrm{H}-5$ because of the splitting pattern as quartet and chemical shift of corresponding carbon peak at $61.4 \mathrm{ppm}$ in the HSQC spectra. The chemical shift for H-6, methyl group, is shown as a triplet of splitting pattern at the lowest frequency at $1.43 \mathrm{ppm}$. The protons at $8.19 \mathrm{ppm}$ were $\mathrm{H}-3^{\prime \prime}, 5^{\prime \prime}$. They correlated with $130.7 \mathrm{ppm}$ of ${ }^{13} \mathrm{C}$ peak at HSQC spectrum and were coupled to both $\mathrm{C}-2^{\prime \prime}, 6^{\prime \prime}$ and $\mathrm{C}-1^{\prime \prime}$ in the HMBC spectrum. The chemical shift for $\mathrm{H}-2^{\prime}, 6^{\prime}(7.54 \mathrm{ppm}(\mathrm{d}, J=8.8 \mathrm{~Hz}))$ was assigned by HMBC correlation with quaternary carbon $\mathrm{C}-1$ (65.6 ppm). Protons $\mathrm{H}-$ $3^{\prime}, 5^{\prime}(7.92 \mathrm{ppm}(\mathrm{d}, J=8.8 \mathrm{~Hz})$ ) were determined from the COSY experiment. The $\mathrm{C}-4^{\prime}$ is long-range coupled to $\mathrm{H}-2^{\prime}, 6^{\prime}$. The chemical shift for $\mathrm{C}-1^{\prime}$ was assigned by HMBC correlation with $\mathrm{H}-3^{\prime}, 5^{\prime}$.

The successful synthesis of the resulting tetrahedral tetraazo-tetracarboxylic acid was confirmed by ${ }^{1} \mathrm{H}$ and ${ }^{13} \mathrm{C}$ NMR 
measurements and corresponding spectra with assignments of hydrogen and carbon atoms are depicted in Fig. 4 and 2D NMR ${ }^{1} \mathrm{H},{ }^{13} \mathrm{C}$-HSQC and ${ }^{1} \mathrm{H},{ }^{13} \mathrm{C}-\mathrm{HMBC}$ spectra are presented in Fig. S5 and S6 in ESI. $\uparrow$ Derivative 7 has a carboxyl group adjacent to carbonyl carbon atom C-4. Carbonyl carbon C-4 was found to correlate with protons $\mathrm{H}-3^{\prime \prime}, 5^{\prime \prime}$ in HMBC spectrum. The chemical shift of $\mathrm{C}-3^{\prime \prime}, 5^{\prime \prime}$ was observed at $130.7 \mathrm{ppm}$. The protons $\mathrm{H}$ $2^{\prime \prime}, 6^{\prime \prime}$ were observed at $7.96 \mathrm{ppm}$, whereas the corresponding carbon appeared at $122.5 \mathrm{ppm}$. The protons $\mathrm{H}-2^{\prime \prime}, 6^{\prime \prime}$ exhibit long-range coupling to the quaternary carbon $\mathrm{C}-4^{\prime \prime}$ at $132.9 \mathrm{ppm}$ and the protons $\mathrm{H}-3^{\prime \prime}, 5^{\prime \prime}$ are long-range coupled to $\mathrm{C}-1$ ". The ${ }^{1} \mathrm{H}$ doublet at $7.59 \mathrm{ppm}$ exhibits a long-range coupling to C-1 (65.2 $\mathrm{ppm}$ ) in the HMBC spectrum suggesting this signal corresponds to $\mathrm{H}-2^{\prime}, 6^{\prime}$. In the HMBC spectrum $\mathrm{H}-2^{\prime}, 6^{\prime}$ also correlate with the carbon at $150.1 \mathrm{ppm}$, which is $\mathrm{C}-4^{\prime}$. This implies that the chemical shift for $\mathrm{H}-3^{\prime}, 5^{\prime}$ is 7.94 ppm. C- $1^{\prime}$ with the chemical shift at $149.2 \mathrm{ppm}$ displays a long-range coupling to the protons $\mathrm{H}-3^{\prime}, 5^{\prime}$. Measured NMR spectra correlate well with a molecular structure of desired tetrahedral linker.

$\mathrm{H}_{4}$ MTA was used for the preparation of UPJS-13 (AS) and UPJS-14 (AS) using zinc(II) and cadmium(II) nitrates at different synthetic conditions. From the structural analysis point of view, our primary goal was to prepare single crystals of studied materials suitable for single-crystal X-ray diffraction experiments. We performed many syntheses (specific synthetic conditions are summarized in Table S1 in ESI†), in which we changed the synthetic conditions: from the molar ratio of reactants, $\mathrm{H}_{4} \mathrm{MTB}$ in the form of carboxylic acid or sodium salt, through reaction time, reaction temperature, different solvents and its volume ratios. The mentioned variable conditions led to the formation of predominantly powdered products, which were not suitable for single-crystal X-ray diffraction experiments. Although aMOFs UPJS-13 and UPJS-14 were prepared in the form of crystals (see Fig. 2) which at first sight appeared to be single crystals, the results of structural measurements (SXRD and PXRD) showed their amorphous character. The best synthetic conditions for the preparation of presented aMOF compounds were found in the mixture of solvent $\mathrm{DMF} / \mathrm{H}_{2} \mathrm{O}$ at $80{ }^{\circ} \mathrm{C}$. The solvent molecules, DMF and water located in the cavities of the prepared compounds were exchanged with ethanol (UPJS-13 (EX) and UPJS-14 (EX)). A third variant of the materials was prepared by the freeze-drying process using benzene (UPJS-13 (FD) and (UPJS-14 (FD)). All described aMOFs materials were subsequently studied by nitrogen adsorption to find the best textural properties and after finding the best activation conditions, the selected compounds were tested as adsorbents for greenhouse gases, carbon dioxide and methane, by high-pressure adsorption measurements.

\subsection{Single crystal and powder X-ray diffraction experiments}

Since the materials were prepared in the form of crystals (see Fig. 2), compounds were first subjected to single-crystal X-ray diffraction analysis to solve their crystal structures. Because the samples did not provide a diffraction image, even after selecting other crystals, the materials were subjected to powder $\mathrm{X}$-ray diffraction (PXRD) experiments. These measurements

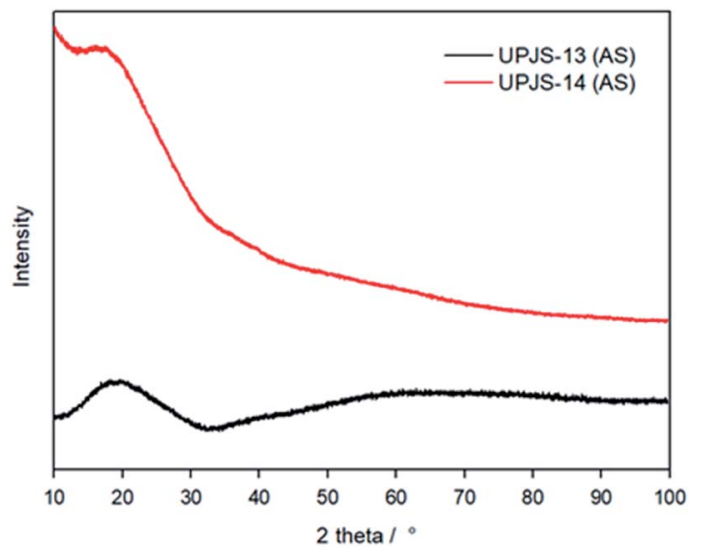

Fig. 5 Powder X-ray diffraction patterns of UPJS-13 (AS) and UPJS-14 (AS).

aimed to confirm the amorphous composition of the whole bulk of prepared materials and confirm their amorphous character. Measured PXRD patterns of materials are shown in Fig. 5 and confirmed their disordered character. Aperiodic arrangements of atoms result in their PXRD patterns being dominated by broad "humps" caused by diffuse scattering and thus they are mostly indistinguishable from one another.

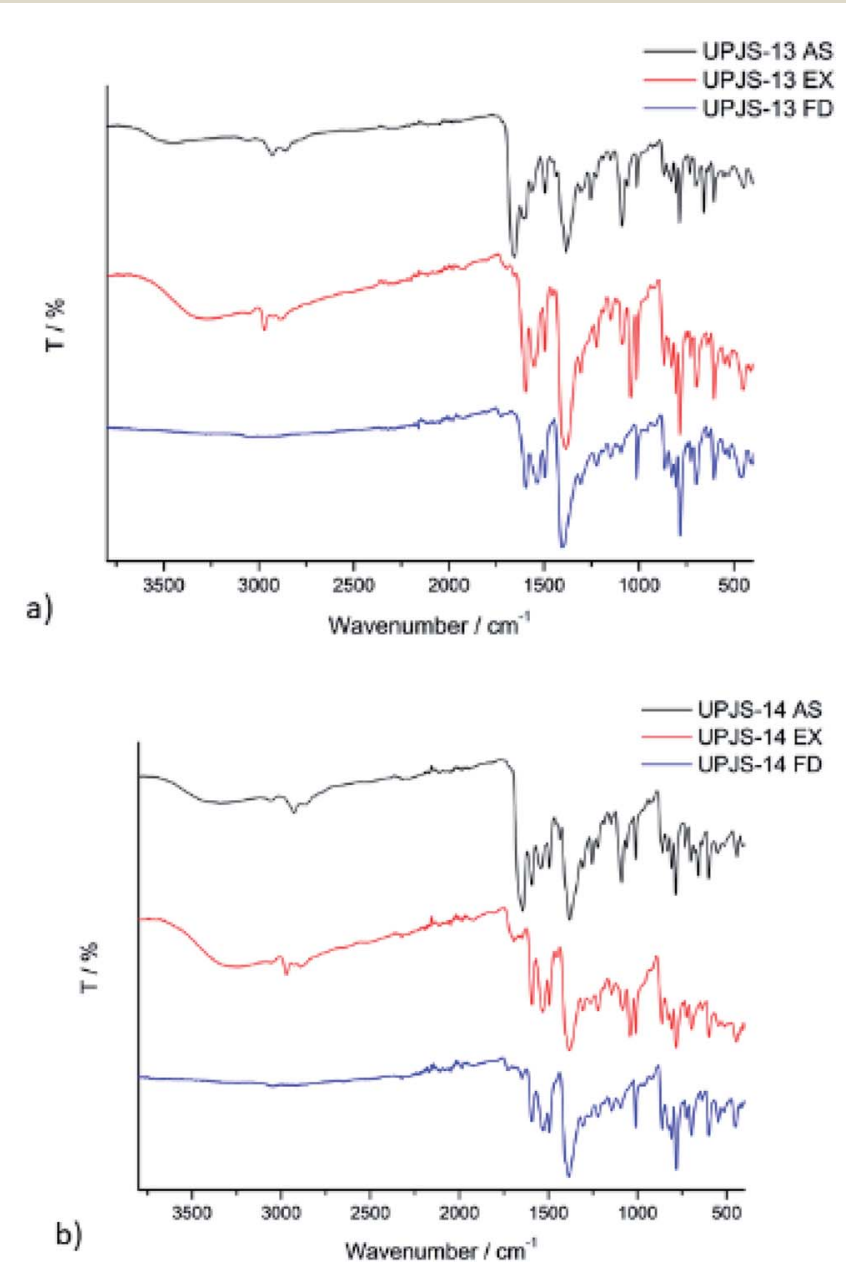

Fig. 6 Infrared spectra of as-synthesized (AS), ethanol exchanged (EX) and freeze-dried (FD) materials of (a) UPJS-13 and (b) UPJS-14. 


\subsection{Infrared spectroscopy}

The infrared spectra of as-synthesized, ethanol exchanged and freeze-dried samples are shown in Fig. 6 and the assignment of absorption bands is summarised in Table 1. The IR spectra of both as-synthesized samples (see Fig. 6, black lines) exhibit broad band centred at about $3400 \mathrm{~cm}^{-1}$ which can be attributed to the $\mathrm{OH}$ stretching vibrations $(\nu(\mathrm{OH}))$ of water molecules, used in the synthesis. The presence of MTA linker in the prepared materials is evident from the intensive adsorption bands at $1603 \mathrm{~cm}^{-1}$ and $1378 \mathrm{~cm}^{-1}$ which can be assigned to antisymmetric and symmetric stretching vibrations of coordinated carboxylate groups $\left(\nu_{\text {as }}\left(\mathrm{COO}^{-}\right)\right.$and $\left.v_{\mathrm{s}}\left(\mathrm{COO}^{-}\right)\right)$. The presence of MTA in prepared materials demonstrated absorption band at $1563 \mathrm{~cm}^{-1}$ for UPJS-13 (AS) and $1543 \mathrm{~cm}^{-1}$ for UPJS-14 (AS) which can be attributed to the $\mathrm{N}=\mathrm{N}$ stretching vibrations of an azo bond. The stretching vibration of aromatic $\mathrm{CH}\left(\nu(\mathrm{CH})_{\mathrm{ar}}\right)$ groups of MTA was found at $3053 \mathrm{~cm}^{-1}$ for UPJS-13 (AS) and $3047 \mathrm{~cm}^{-1}$ for UPJS-14 (AS). The stretching vibrations of aliphatic $\mathrm{CH}$ groups $\left(\nu(\mathrm{CH})_{\text {aliph }}\right)$ of DMF molecules adsorbed in the porous system of samples were observed in the region under $3000 \mathrm{~cm}^{-1}$ (2926 and $2853 \mathrm{~cm}^{-1}$ for UPJS-14 (AS); 2929 and $2850 \mathrm{~cm}^{-1}$ for UPJS-14 (AS)). The presence of DMF is also evident from the strong absorption band of carbonyl group $\nu(\mathrm{C}=\mathrm{O})$ located at $1656 \mathrm{~cm}^{-1}$ and the $\nu(\mathrm{C}-\mathrm{N})$ vibration at $1253 \mathrm{~cm}^{-1}$ for both compounds. In the IR spectra of ethanol exchanged samples (see Fig. 6, red lines) absorption bands belonging to the MTA linker are still present, but the characteristic vibration $\nu(\mathrm{C}=\mathrm{O})$ around $1650 \mathrm{~cm}^{-1}$ for DMF molecules is no longer present. Described observation confirms the successful exchange of DMF molecules for ethanol. Ethanol molecules in the IR spectra showed a shift in $\nu(\mathrm{OH})$ vibration to lower wavelength values $\left(3277 \mathrm{~cm}^{-1}\right.$ for UPJS-13 (EX) and $3260 \mathrm{~cm}^{-1}$ for UPJS-14 (EX)) and also new aliphatic $\nu(\mathrm{CH})_{\mathrm{aliph}}$ vibrations appeared under $2930 \mathrm{~cm}^{-1}$. In the IR spectra of freeze-dried compounds (see Fig. 6, blue lines), no characteristic absorption bands originated from DMF or ethanol are present, which confirm the successful activation of UPJS-13 and UPJS-14 materials.

\subsection{Thermal stability study}

The thermal behaviour and stability of as-synthesized, ethanol exchanged and freeze-dried compounds were investigated using thermogravimetry and obtained TG curves are shown in Fig. 7. The AS samples (see black curves in Fig. 7) are thermally stable after heating to $80{ }^{\circ} \mathrm{C}$, above this temperature in the temperature range $80-380{ }^{\circ} \mathrm{C}$ desolvation processes take place in two
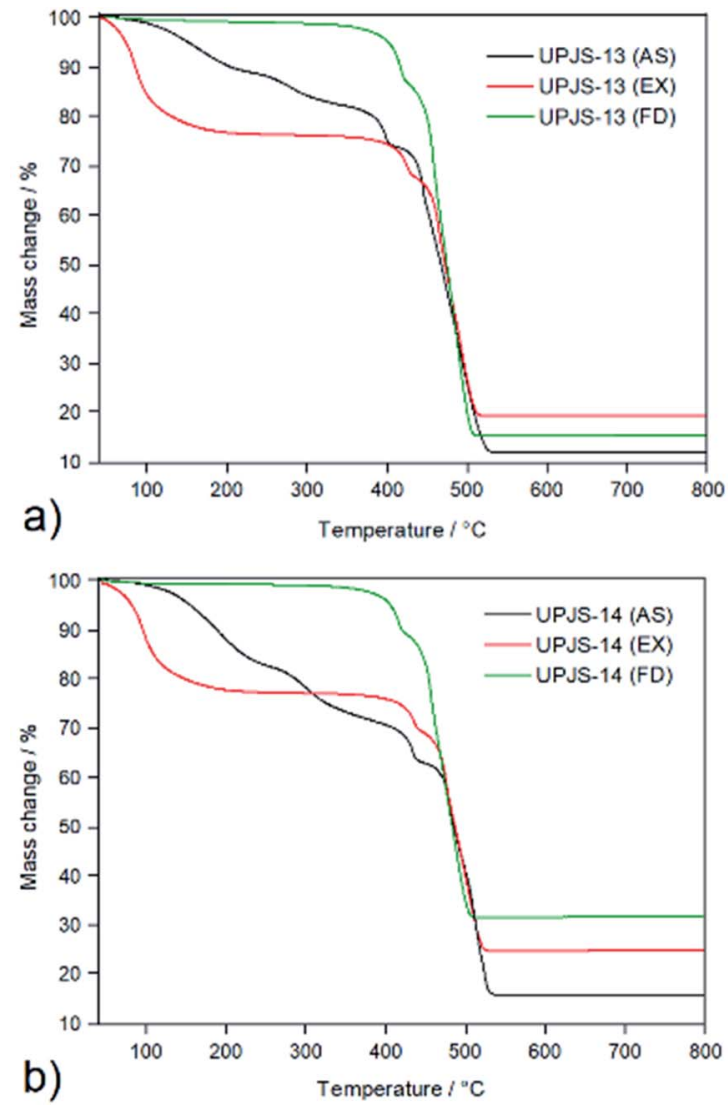

Fig. 7 Thermogravimetric curves of as-synthesized, ethanol exchanged and freeze-dried samples of (a) UPJS-13 and (b) UPJS-14 measured in an air atmosphere and temperature range of $30-800^{\circ} \mathrm{C}$.

Table 1 Assignment of vibrations and corresponding wavenumbers to characteristic absorption bands in IR spectra of prepared and pretreated materials $^{a}$

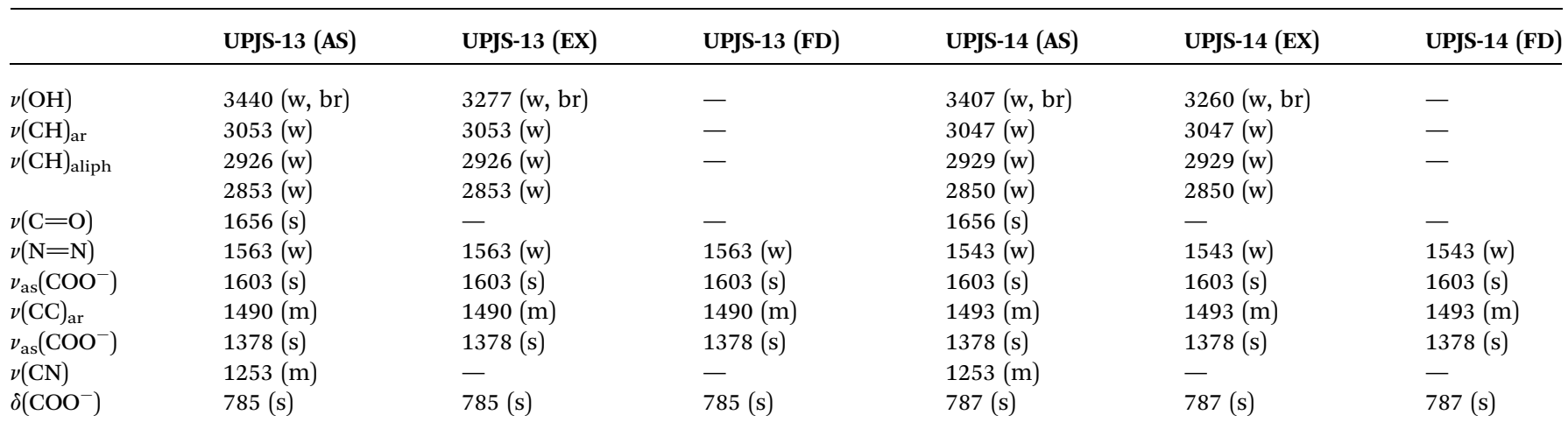

${ }^{a} \mathrm{w}$ - weak, $\mathrm{m}$ - medium, s - strong, br - broad, ar - aromatic, aliph - aliphatic, s - symmetric, as - antisymmetric. 
overlapping decomposition steps. In mentioned range total mass loss of $21.6 \mathrm{wt} \%$ for UPJS-13 (AS) and $32.0 \mathrm{wt} \%$ for UPJS-14 (AS) was observed and correspond to release of solvent molecules $\left(3 \times\right.$ DMF, $4 \times \mathrm{H}_{2} \mathrm{O}$, clcd. mass loss $21.9 \mathrm{wt} \%$ for UPJS-13 (AS); $4 \times$ DMF, $5 \times \mathrm{H}_{2} \mathrm{O}$, clcd. mass loss $31.8 \mathrm{wt} \%$ for UPJS-14 (AS)). Further heating led to the decomposition of frameworks, which occurs in $380-530{ }^{\circ} \mathrm{C}$. Final thermal decomposition products were $\mathrm{ZnO}$ (observed residual mass $12.6 \mathrm{wt} \%$, clcd. residual mass $\mathbf{1 2 . 2} \mathrm{wt} \%$ for UPJS-13 (AS)) and CdO (observed residual mass $17.4 \mathrm{wt} \%$, clcd. residual mass $16.9 \mathrm{wt} \%$ for UPJS14 (AS)). The desolvation process in ethanol exchanged samples takes place at a lower temperature (see red curves in Fig. 7), the release of ethanol molecules starts at the beginning of heating and complete desolvation occurs about $180{ }^{\circ} \mathrm{C}$. The desolvated forms of UPJS-13 (EX) and UPJS-14 (EX) are thermally stable from $180-420^{\circ} \mathrm{C}$ as is seen from the plateau on TG curves. The decomposition of polymeric frameworks takes place in two overlapping decomposition steps, similarly to the assynthesized samples. As can be seen from obtained TG curves for EX materials, the solvent exchange process significantly impacts the compounds' activation temperature. The TG curves of the freeze-dried samples (see green curves in Fig. 7) confirm the successful activation of the compounds, as no weight loss is observed in the temperature range $30-420{ }^{\circ} \mathrm{C}$. The decomposition of UPJS-13 (FD) and UPJS-14 (FD) frameworks, [ $\mathrm{Zn}_{2}(\mathrm{MTA})$ ] and $\left[\mathrm{Cd}_{2}(\mathrm{MTA})\right]$, takes place in temperature range $420-530{ }^{\circ} \mathrm{C}$ with residual masses $\mathbf{1 5 . 5} \mathrm{wt} \%$ and $33.9 \mathrm{wt} \%$ corresponding to the formation of $\mathrm{ZnO}$ and $\mathrm{CdO}$ as final decomposition products (clcd. residual masses $15.7 \mathrm{wt} \%$ for $\mathrm{ZnO}$ and $34.4 \mathrm{wt} \%$ for $\mathrm{CdO}$ ).

\subsection{Solid-state NMR spectroscopy}

The formation of interactions/bonds between the building blocks in the prepared aMOF materials was also studied by solid-state NMR (sSNMR) spectroscopy. A comparison of the ${ }^{13} \mathrm{C}$

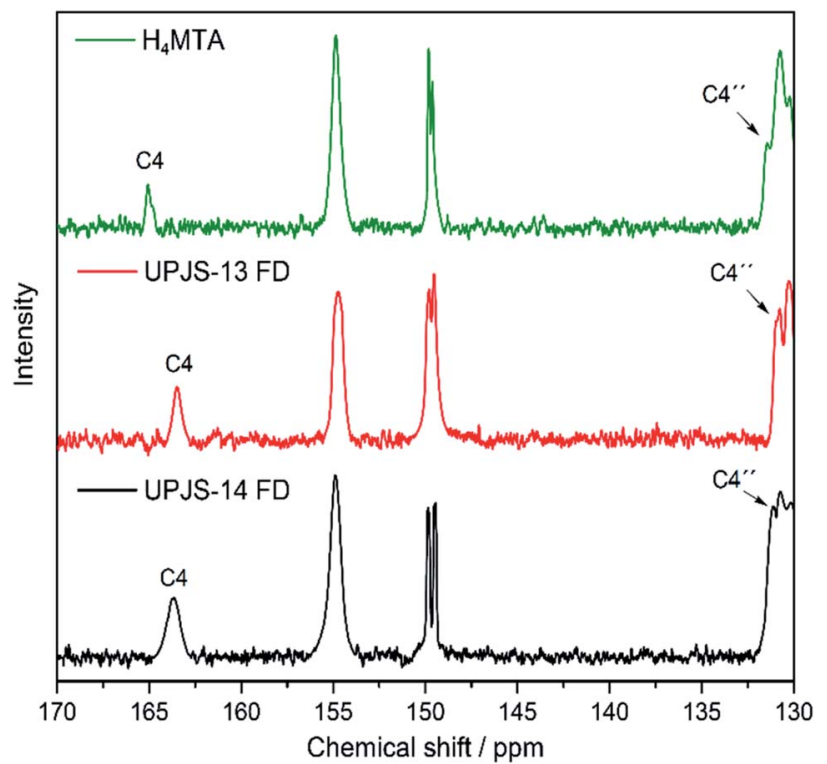

Fig. 8 Assignment of the signals to the carbon atoms in $\mathrm{H}_{4}$ MTA and activated forms of UPJS-13 and UPJS-14 in ${ }^{13} \mathrm{C} \mathrm{CP/MAS} \mathrm{NMR} \mathrm{spectra.}$
CP/MAS NMR spectra of the linker $\left(\mathrm{H}_{4} \mathrm{MTA}\right)$ and the freezedried materials UPJS-13 and UPJS-14 are shown in Fig. 8. The ${ }^{13} \mathrm{C}$ NMR spectra of $\mathrm{H}_{4}$ MTA measured in the liquid (see Fig. 4) and solid phases (see Fig. 8) show differences in the chemical shifts of the individual signals, which are mostly shifted in the solid phase to lower values. Changes in the position of the NMR signals can be explained by the formation of intermolecular interactions ${ }^{52}$ between $\mathrm{H}_{4}$ MTA molecules in the solid-state. However, it should be noted that the particle size of the material used for measurement can also affect the position of the signals in the resulting NMR spectrum. ${ }^{53}$ Significant differences were observed for the carbonyl carbon (C4) signal, which shifts $2.6 \mathrm{ppm}$ lower from the original value $(166.7 \mathrm{ppm})$ in the liquid phase. This observation can be explained by the formation of dimers between the carboxyl groups of $\mathrm{H}_{4}$ MTA molecules with each other. ${ }^{54}$ Significant changes in chemical shifts occur after coordination of the MTA linker to $\mathrm{Zn}$ (II) and $\mathrm{Cd}$ (II) ions, when significant changes in the signal positions of the carbon atoms $\mathrm{C} 4$ and $\mathrm{C}^{\prime \prime}$ were observed (see Fig. 8). Since $\mathrm{Zn(II)}$ and $\mathrm{Cd}(\mathrm{II})$ ions are diamagnetic metals, they do not show so significant changes in chemical shifts after coordination of linker molecules compared to the paramagnetic ions. ${ }^{55-58}$ Nevertheless, based on the described changes of chemical shifts in the ${ }^{13} \mathrm{C} \mathrm{CP} /$ MAS NMR spectra of $\mathrm{H}_{4}$ MTA and prepared compounds, the formation of a coordination bond between the building blocks can be confirmed.

\subsection{Gas adsorption}

3.6.1 Nitrogen adsorption measurements. To investigate the porosity of prepared aMOFs, nitrogen adsorption measurements at $-196{ }^{\circ} \mathrm{C}$ were performed. The adsorption measurements were realised on as-synthesized (AS), ethanol
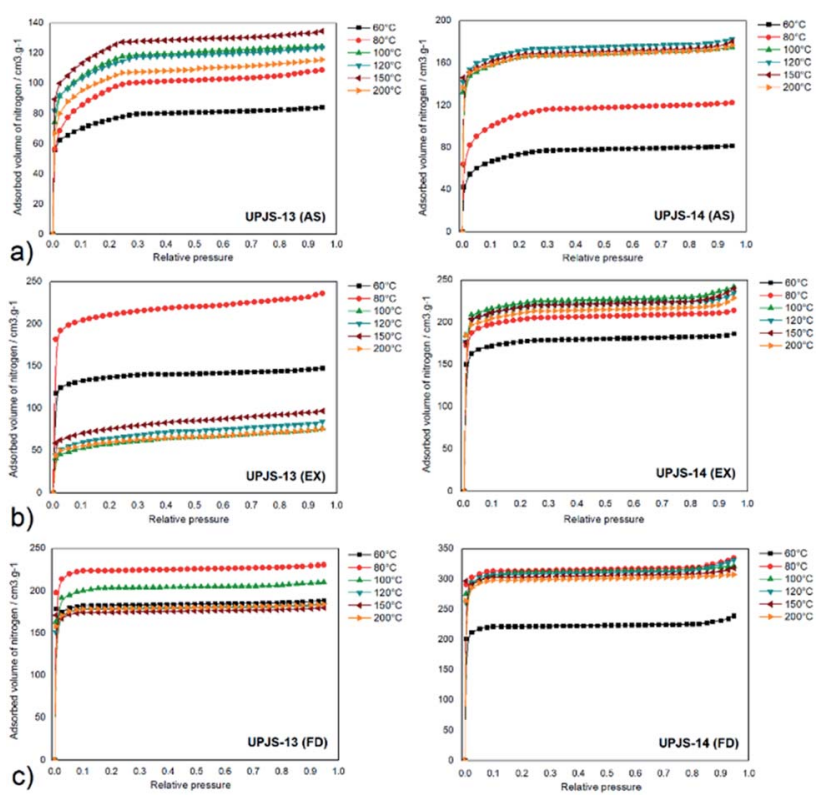

Fig. 9 Nitrogen adsorption isotherms of (a) as-synthesized, (b) ethanol exchanged and (c) freeze-dried samples of UPJS-13 and UPJS-14 after activation at 60, 80, 100, 120, 150 and $200{ }^{\circ} \mathrm{C}$. 
exchanged (EX) and freeze-dried (FD) samples. Ethanol exchanged samples were prepared by immersing of assynthesized materials in ethanol. Freeze-dried samples were prepared after replacing high boiling point solvent (DMF, b.p. $153.0^{\circ} \mathrm{C}$ ) inside the channels of prepared materials for benzene (b.p. $80.1{ }^{\circ} \mathrm{C}$, m.p. $5.5^{\circ} \mathrm{C}$ ). Samples were further frozen and benzene was removed under vacuum by sublimation. Samples prepared by the described procedure were thermally activated at different temperatures $\left(60,80,100,120,150\right.$ and $\left.200{ }^{\circ} \mathrm{C}\right)$ under vacuum for $12 \mathrm{~h}$. Obtained adsorption isotherms are presented in Fig. 9 and calculated BET surface areas $\left(S_{\mathrm{BET}}\right)$ are summarised in Table 2 and shown in Fig. 10. The nitrogen adsorption measurements revealed a type I isotherm according to IUPAC classification, typical for microporous materials. The small difference in the shape of measured and ideal isotherm could be explained by the presence of weaker attractive forces between nitrogen molecules with pore walls or by the nitrogen interaction with a variety of active surface sites and other vacant sites formed during the activation procedures (dislocation, defects, electron-rich azo group).

For as-synthesized materials containing DMF/water molecules in the pores, it is characteristic that as the activation temperature increases, the surface area gradually increases up to $100{ }^{\circ} \mathrm{C}$ (see black curves in Fig. 10a). Above this temperature, there is no more pronounced increase in $S_{\mathrm{BET}}$ and the values are almost constant. This is caused by the gradual removal of solvent molecules from the pore system of materials. The calculated surface area at $100{ }^{\circ} \mathrm{C}$ were $415 \mathrm{~m}^{2} \mathrm{~g}^{-1}$ for UPJS-13 (AS) and $629 \mathrm{~m}^{2} \mathrm{~g}^{-1}$ for UPJS-14 (AS). After activating samples at $200{ }^{\circ} \mathrm{C}$, a slight decrease in surface area was observed (see Fig. 9, Table 2).

For UPJS-13 (EX), the trend in surface area values at selected activation temperature is different. The maximum $S_{\mathrm{BET}}$ of 721 $\mathrm{m}^{2} \mathrm{~g}^{-1}$ was reached at $80{ }^{\circ} \mathrm{C}$ and by subsequent heating at $100^{\circ} \mathrm{C}$ decreases to the value of $210 \mathrm{~m}^{2} \mathrm{~g}^{-1}$. The further increase in temperature does not have a significant effect on the textural

Table 2 The summary of calculated specific surface areas $\left(S_{\mathrm{BET}}\right)$ for UPJS-13 and UPJS-14 after activation process at different temperatures

$\underline{S_{\mathrm{BET}} \text { surface area }\left(\mathrm{m}^{2} \mathrm{~g}^{-1}\right)}$

Activation temperature $\left({ }^{\circ} \mathrm{C}\right)$

\begin{tabular}{lllllll} 
Sample & 60 & 80 & 100 & 120 & 150 & 200 \\
\hline
\end{tabular}

\begin{tabular}{lllllll}
\hline $\begin{array}{l}\text { As-synthesized } \\
\text { UPJS-13 (AS) }\end{array}$ & 154 & 349 & 415 & 404 & 448 & 375 \\
UPJS-14 (AS) & 254 & 405 & 629 & 656 & 621 & 613 \\
& & & & & & \\
Exchanged & & & & & & \\
UPJS-13 (EX) & 447 & 721 & 210 & 237 & 280 & 225 \\
UPJS-14 (EX) & 681 & 767 & 880 & 862 & 869 & 851 \\
& & & & & & \\
Freeze dried & & & & & & \\
UPJS-13 (FD) & 648 & 830 & 769 & 623 & 618 & 615 \\
UPJS-14 (FD) & 754 & 1057 & 1052 & 1024 & 1013 & 989
\end{tabular}
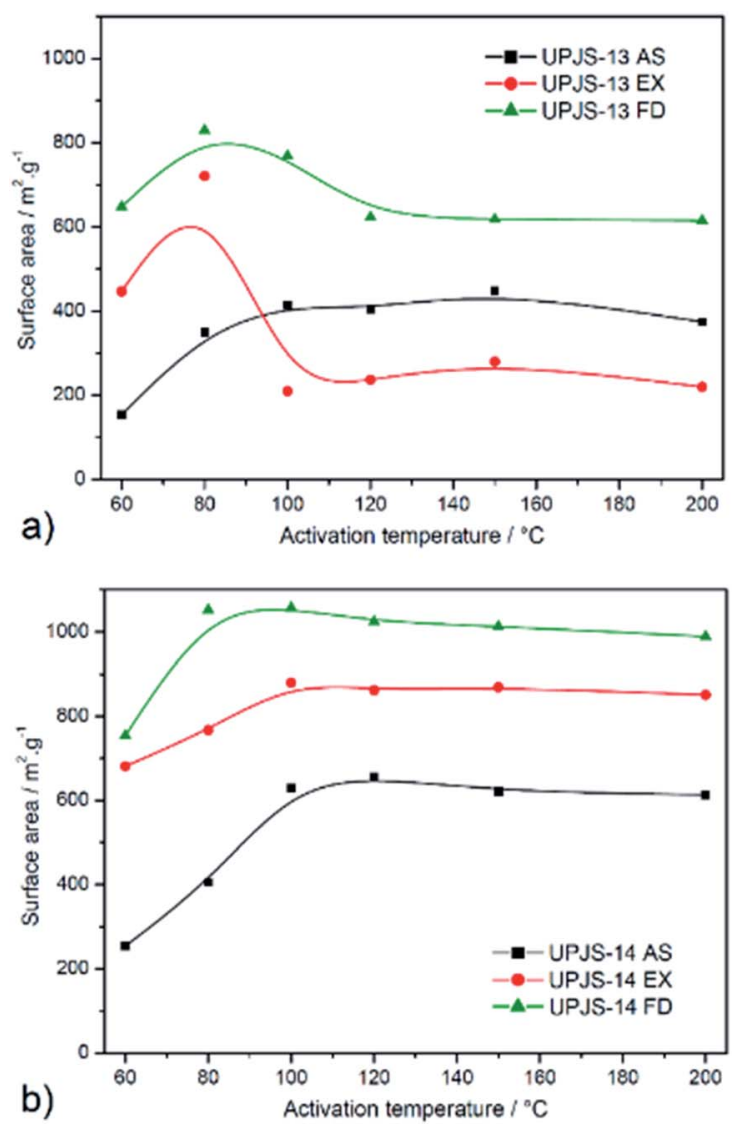

Fig. 10 Calculated BET surface areas from nitrogen isotherms of activated materials at $60,80,100,120,150$ and $200^{\circ} \mathrm{C}$ for (a) UPJS-13 and (b) UPJS-14.

properties (see red curves in Fig. 10), probably due to the collapse of the polymer framework. Because ethanol has a low boiling point, its release at $100{ }^{\circ} \mathrm{C}$ occurs all at once, which lead to pore perforation associated with the destruction of the framework. The sample UPJS-14 (EX) showed similar behaviour compared to UPJS-14 (AS) and gradually increased the $S_{\mathrm{BET}}$ with increasing temperature up to $80{ }^{\circ} \mathrm{C}$ and the maximal surface area after activation at $100{ }^{\circ} \mathrm{C}$ was $880 \mathrm{~m}^{2} \mathrm{~g}^{-1}$.

The best textural properties were observed for materials after the freeze-drying process (see green curves in Fig. 10). The highest values of surface areas were calculated after activation of the samples at $80^{\circ} \mathrm{C}$ (see green curves in Fig. 10, Table 2) and corresponding values were $830 \mathrm{~m}^{2} \mathrm{~g}^{-1}$ (pore volume, $V_{\mathrm{p}}=0.57$ $\mathrm{cm}^{3} \mathrm{~g}^{-1}$; pore diameter, $d=0.73 \mathrm{~nm}$ calculated by DFT) for UPJS-13 (FD) and $1057 \mathrm{~m}^{2} \mathrm{~g}^{-1}$ (pore volume, $V_{\mathrm{p}}=0.72 \mathrm{~cm}^{3} \mathrm{~g}^{-1}$; pore diameter, $d=0.87 \mathrm{~nm}$ calculated by DFT) for UPJS-14 (FD). Gradual heating to $120{ }^{\circ} \mathrm{C}$ leads to a slight decrease in $S_{\mathrm{BET}}$ values and further heating did not affect the values of surface area for both compounds.

It is to note, that the observed $S_{\mathrm{BET}}$ values for UPJS-13 and UPJS-14 are higher compared with MOFs constructed from shorter tetrahedral linker, methanetetrabenzoate (MTB) containing $\mathrm{Ca}$ (II) $\left(126 \mathrm{~m}^{2} \mathrm{~g}^{-1}\right),{ }^{59} \mathrm{Zn}$ (II) $\left(248 \mathrm{~m}^{2} \mathrm{~g}^{-1}\right){ }^{46} \mathrm{Co}$ (II) $\left(356 \mathrm{~m}^{2}\right.$ $\left.\mathrm{g}^{-1}\right){ }^{60} \mathrm{Ba}$ (II) $\left(358 \mathrm{~m}^{2} \mathrm{~g}^{-1}\right),{ }^{59} \mathrm{Cu}$ (II) $\left(526 \mathrm{~m}^{2} \mathrm{~g}^{-1}\right)^{40}$ and $\mathrm{Ni}(\mathrm{II})(700$ 
$\left.\mathrm{m}^{2} \mathrm{~g}^{-1}\right)^{61}$ ions. A further comparison could be performed with a copper(II) MOF $\left[\mathrm{Cu}_{2}(\mathrm{MTC})\left(\mathrm{H}_{2} \mathrm{O}\right)_{2}\right] \cdot 14 \mathrm{DMF} \cdot 5 \mathrm{H}_{2} \mathrm{O},{ }^{40}$ which contains similar extended tetrahedral linker MTC (methanetetra(biphenyl- $p$-carboxylate) to MTA described in the present study. The methanol exchanged and vacuum dried compounds, both activated at $60{ }^{\circ} \mathrm{C}$ exhibited surface area of $791 \mathrm{~m}^{2} \mathrm{~g}^{-1}$ and its freeze-dried form $1020 \mathrm{~m}^{2} \mathrm{~g}^{-1}$. The zinc(II) analogue with formulae $\left[\mathrm{Zn}_{2}(\mathrm{MTC})\left(\mathrm{H}_{2} \mathrm{O}\right)_{2}\right]$ may also be mentioned, which exhibited after dichloromethane exchange a surface area of $1170 \mathrm{~m}^{2} \mathrm{~g}^{-\mathbf{1}_{62}}$ and calculated $S_{\mathrm{BET}}$ is similar to UPJS-14 (FD). The highest reported surface area was published for zirconium(Iv) MOF containing MTC linker with a composition of $\left[\mathrm{Zr}_{6}(-\right.$ $\left.\mathrm{OH})_{16}(\mathrm{MTC})_{2}\right]$ and $S_{\mathrm{BET}}=3411 \mathrm{~m}^{2} \mathrm{~g}^{-1} \cdot{ }^{63,64,74}$

In summary, it can be concluded that UPJS-14 material showed better textural properties compared to UPJS-13, regardless of the post-synthetic treatment and activation conditions. The highest values of surface areas of prepared materials were observed for samples after the freeze-drying process, followed by ethanol-exchanged and as-synthesized samples. Compound UPJS-14 (FD) activated at $80{ }^{\circ} \mathrm{C}$ exhibited large surface area compared with other reported MOF compounds containing similar extended tetrahedral linker.

3.6.2 High-pressure carbon dioxide and methane adsorption measurements. As major components of greenhouse gases, carbon dioxide and methane have also been studied as probe molecules to investigate the sorption properties of prepared aMOFs. $\mathrm{CO}_{2}$ and $\mathrm{CH}_{4}$ high-pressure adsorption measurements were performed at $30{ }^{\circ} \mathrm{C}$ and pressure up to 20 bar on freezedried samples activated at $80{ }^{\circ} \mathrm{C}$. Measured adsorption isotherms are shown in Fig. 11 and obtained maximal adsorption capacities at 1 and 20 bar are summarised in Table 3. The absence of district plateaus in the isotherms indicated that the maximal capacities were still not achieved and compounds are not saturated by the gases at 20 bar. Both selected probes are non-polar molecules with different quadrupole moments $(0 \mathrm{C}$ $\mathrm{m}^{2}$ for $\mathrm{CH}_{4}, 14.3 \times 10^{40} \mathrm{C} . \mathrm{m}^{2}$ for $\left.\mathrm{CO}_{2}\right)$, kinetic diameters $(3.8 \AA$

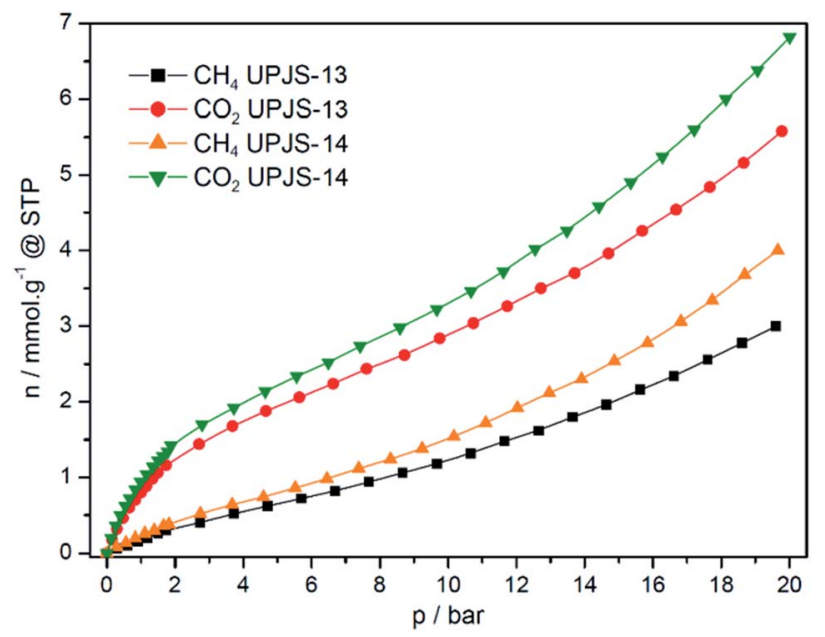

Fig. 11 Methane and carbon dioxide high-pressure adsorption isotherms of UPJS-13 and UPJS-14 measured at $30{ }^{\circ} \mathrm{C}$ and pressure up to 20 bar.
Table 3 Adsorbed amount (in mmol g ${ }^{-1}$ and $w t \%$ ) of $\mathrm{CO}_{2}$ and $\mathrm{CH}_{4}$ at $30{ }^{\circ} \mathrm{C}$ and pressure $1 / 20$ bar in freeze-dried compounds after activation at $80^{\circ} \mathrm{C}$

\begin{tabular}{|c|c|c|c|c|c|}
\hline & \multirow[b]{2}{*}{ Bar } & \multicolumn{2}{|l|}{$\mathrm{CO}_{2}$} & \multicolumn{2}{|l|}{$\mathrm{CH}_{4}$} \\
\hline & & $\mathrm{mmol} \mathrm{g}^{-1}$ & wt $\%$ & $\mathrm{mmol} \mathrm{g}^{-1}$ & wt $\%$ \\
\hline \multirow[t]{2}{*}{ UPJS-13 (FD) } & 1 & 0.94 & 4.14 & 0.22 & 0.35 \\
\hline & 20 & 6.82 & 30.1 & 2.21 & 1.4 \\
\hline \multirow[t]{2}{*}{ UPJS-14 (FD) } & 1 & 0.80 & 3.52 & 0.36 & 0.58 \\
\hline & 20 & 5.58 & 24.56 & 3.98 & 6.38 \\
\hline
\end{tabular}

for $\mathrm{CH}_{4}, 3.3 \AA$ for $\left.\mathrm{CO}_{2}\right)$ and different boiling points $\left(-161^{\circ} \mathrm{C}\right.$ for $\mathrm{CH}_{4},-78{ }^{\circ} \mathrm{C}$ for $\mathrm{CO}_{2}$ ) and described differences may influence the maximal adsorption uptake of gases.

aMOFs storage capacities of carbon dioxide at 1 bar and $30{ }^{\circ} \mathrm{C}$ were $0.94 \mathrm{mmol} \mathrm{g}^{-1}(4.14 \mathrm{wt} \%)$ for UPJS-13 FD and $0.8 \mathrm{mmol} \mathrm{g}^{-1}$ (3.52 wt\%) for UPJS-14 FD. With increasing pressure, an increase in the amount of adsorbed carbon dioxide was observed. The maximal adsorption uptake and corresponding adsorption capacities were $6.82 \mathrm{mmol} \mathrm{g}^{-1}$ (30.01 wt\%) for UPJS-13 FD and $5.58 \mathrm{mmol} \mathrm{g}^{-1}(24.56 \mathrm{wt} \%)$ for UPJS-14 FD at $30{ }^{\circ} \mathrm{C}$ and 20 bar. Both compounds show high $\mathrm{CO}_{2}$ storage capacities, however, the UPJS-13 FD framework showed a higher affinity for $\mathrm{CO}_{2}$ compared to UPJS-14 FD, although it has a smaller surface area. Due to the presence of an electrondeficient carbon atom, carbon dioxide is expected to interact with protic electronegative functional groups, leading to strong chemisorption. This simple interaction has so far led to a number of nanoporous polymers in which nitrogen-rich functions are incorporated, such as triazine, ${ }^{\mathbf{6 5 , 6 6}}$ tetrazole, ${ }^{\mathbf{6 7}}$ imidazole, ${ }^{68,69}$ imide $^{70}$ and amines. ${ }^{42,71}$ Increased $\mathrm{CO}_{2}$ adsorption capacity in UPJS-13 (FD) and UPJS-14 (FD) can be explained by an interaction between $\mathrm{CO}_{2}$ molecules and adsorption sites represented by a lone pair on the azo functional groups located in the molecular structure of the MTA linker. In the case of azo group, the interaction with $\mathrm{CO}_{2}$ was also confirmed by computational studies, in which the relative binding affinity of $\mathrm{CO}_{2}$ to the $-\mathrm{N}=\mathrm{N}$ - group using trans-azobenzene as a model system were performed. Calculations have shown that the lowest energy structure of the $\mathrm{CO}_{2} /$ trans-azobenzene complex indicates that carbon dioxide preferentially binds to the azo group of trans-azobenzene by physisorption with a binding energy of $17.0 \mathrm{~kJ} \mathrm{~mol}^{-1}$. $\mathrm{CO}_{2}$ also has a favourable interaction with the aromatic ring, including a large stabilizing energy, $14.4 \mathrm{~kJ} \mathrm{~mol}^{-1} .^{72}$ It is known that MOFs with coordinatively unsaturated sites (CUSs) offer interesting possibilities for tuning the affinity of these materials towards certain adsorbates, potentially increasing their selectivity and storage capacity. ${ }^{73}$ In MOFs with CUSs, at least one available coordination site of the metal centre is occupied by an atom belonging to a solvent molecule. The solvent molecules can be removed through the activation process, leaving the metal atom with an open coordination site. Examples are $\mathrm{Zn}$ (II) and $\mathrm{Cd}(\mathrm{II})$ compounds, which have been constructed with methanetetrabenzoate (MTB, short tetrahedral carboxylate linker 
compared to MTA) with compositions: $\left[\mathrm{Zn}_{2}(\mathrm{MTB})\left(\mathbf{H}_{2} \mathbf{O}\right)_{2}\right]$. $3 \mathrm{H}_{2} \mathrm{O} \cdot 3 \mathrm{DMF}^{46}$ and $\left[\mathrm{Cd}_{4}(\mathrm{MTB})_{2}(\mathrm{DMF})_{4}\right] \cdot 4 \mathrm{DMF} \cdot 4 \mathrm{H}_{2} \mathrm{O} .^{64,74}$ The framework of zinc form imitates the PtS structure and contains paddle-wheel cluster $(2 \times$ CUSs, bold text in the formula) and the cadmium framework mimics the fluorite $\left(\mathrm{CaF}_{2}\right)$ structure, which contains a tetranuclear cluster containing four terminally coordinated solvent molecules $(4 \times$ CUSs, bold text in the formula). We can only speculate, that the increased affinity of $\mathrm{CO}_{2}$ for the presented aMOFs is the presence of CUSs on $\mathrm{Zn}$ (II) and $\mathrm{Cd}(\mathrm{II})$ ions in the frameworks of UPJS-13 and UPJS-14.

According to the literature data, the high-pressure $\mathrm{CO}_{2}$ adsorption measurements were performed for two compounds containing MTB linker. Nickel(II) MOF $\left(S_{\text {BET }}=700 \mathrm{~m}^{2} \mathrm{~g}^{-1}\right)$ adsorbed $18.05 \mathrm{wt} \%\left(4.1 \mathrm{mmol} \mathrm{g}^{-1}\right)$ of $\mathrm{CO}_{2}$ (ref. 61) and lead(II) compound $\left(S_{\mathrm{BET}}=980 \mathrm{~m}^{2} \mathrm{~g}^{-1}\right) 19.81 \mathrm{wt} \%\left(4.5 \mathrm{mmol} \mathrm{g}^{-1}\right)$ of $\mathrm{CO}_{2}$ (ref. 75 and 76) at $30{ }^{\circ} \mathrm{C}$ and 21 bar. The highest to date $\mathrm{CO}_{2}$ storage capacities were reported for the following unmodified MOFs: UiO(dpdc) (dpdc $=2,2^{\prime}$-bipyridine-5, $5^{\prime}$-dimethyl, $S_{\mathrm{BET}}=$ $\left.2646 \mathrm{~m}^{2} \mathrm{~g}^{-1}\right)^{77} 18.11 \mathrm{mmol} \mathrm{g}^{-1}(79.7 \mathrm{wt} \%)$ at $30{ }^{\circ} \mathrm{C}$ and $20 \mathrm{bar}$; NU-111 (Cu(4-PmBC), 4-PmBC $=4$-(pyrimidin-5-yl)benzoate, $\left.S_{\mathrm{BET}}=4932 \mathrm{~m}^{2} \mathrm{~g}^{-1}\right)^{78} 14.04 \mathrm{mmol} \mathrm{g}^{-1}(61.8 \mathrm{wt} \%)$ at $25{ }^{\circ} \mathrm{C}$ and 30 bar; DGC-MIL-101 (DGC = dry gel conversion, Cr(BDC), BDC = benzene-1,4-dicarboxylate, $\left.S_{\mathrm{BET}}=4198 \mathrm{~m}^{2} \mathrm{~g}^{-1}\right)^{79}$ $13.59 \mathrm{mmol} \mathrm{g}^{-1}(59.8 \mathrm{wt} \%)$ at $25{ }^{\circ} \mathrm{C}$ and 40 bar and DMOF $\left(\mathrm{Zn}_{2}(\mathrm{BDC})_{2}(\mathrm{DABCO}), \mathrm{DABCO}=1,4\right.$-diazabicyclo[2.2.2]octane, $\left.S_{\mathrm{BET}}=1980 \mathrm{~m}^{2} \mathrm{~g}^{-1}\right)^{80} 8.66 \mathrm{mmol} \mathrm{g}^{-1}(38.1 \mathrm{wt} \%)$ at $25^{\circ} \mathrm{C}$ and 20 bar.

Methane is the main component of natural gas and the second most abundant greenhouse gas in Earth's atmosphere. $\mathrm{CH}_{4}$ is a non-polar molecule with zero quadrupole moment and has a low volumetric energy density, which poses a challenge for efficient storage to reduce its concentration in the atmosphere or for energy application. For this reason, methane was also used as an adsorbate for high-pressure adsorption and measured isotherms are presented in Fig. 11. Materials adsorb methane with a maximal storage capacity of $0.22 \mathrm{mmol} \mathrm{g}^{-1}$ (0.35 wt\%) for UPJS-13 (FD) and $0.36 \mathrm{mmol} \mathrm{g}^{-1}(0.58 \mathrm{wt} \%)$ for UPJS-14 (FD) at $30^{\circ} \mathrm{C}$ and $1 \mathrm{bar}$ and $3.02 \mathrm{mmol} \mathrm{g}^{-1}$ (4.84 wt\%) for UPJS-13 (FD) and $3.98 \mathrm{mmol} \mathrm{g}^{-1}(6.38 \mathrm{wt} \%)$ for UPJS-14 (FD) at $30{ }^{\circ} \mathrm{C}$ and 20 bar. It could be noted that the adsorbed amounts are approximately four/five times lower compared to carbon dioxide. Contrary, the values of stored $\mathrm{CH}_{4}$ are relatively high and can be explained by the pore size of aMOF materials. Several theoretical studies have shown that the optimum pore size for methane storage is $8 \AA$, which corresponds to distance between pore walls of about twice larger, than the molecule diameter. ${ }^{81,82}$ As it was described above, the effective pore size of UPJS-13 (FD) and UPJS-14 (FD) based on nitrogen adsorption are 7.3 and $8.7 \AA$; thus it could be an explanation for increased $\mathrm{CH}_{4}$ adsorption.

A comparison of the adsorption capacity with compounds containing shorter tetrahedral carboxylate linker (MTB) has shown that the $\mathrm{CH}_{4}$ adsorption capacities were reported for $\mathrm{Ni}(\mathrm{II})^{61}$ and $\mathrm{Pb}(\mathrm{II})^{75}$ compounds with a methane storage capacity of $3.29 \mathrm{wt} \%\left(2.05 \mathrm{mmol} \mathrm{g}^{-1}\right)$ and $3.05 \mathrm{wt} \%\left(1.9 \mathrm{mmol} \mathrm{g}^{-1}\right)$ at $30{ }^{\circ} \mathrm{C}$ and 21 bar, respectively. The highest documented $\mathrm{CH}_{4}$ capacities were reported for NU-125 $\left(\mathrm{Cu}(\mathrm{BTTI})\right.$, BTTI $=5,5^{\prime}, 5^{\prime \prime}$ -
(4,4', $4^{\prime \prime}$-(benzene-1,3,5-triyl)tris(1H1,2,3-triazole-4,1-diyl)) triisophthalate, $\left.S_{\mathrm{BET}}=3120 \mathrm{~m}^{2} \mathrm{~g}^{-1}\right)^{83}$ which can store $11.47 \mathrm{mmol} \mathrm{g}^{-1}(18.40 \mathrm{wt} \%)$ at $25{ }^{\circ} \mathrm{C}$ and 20 bar and BUT-22 $\left(\mathrm{Al}_{3}(\mathrm{O})(\mathrm{OH})\left(\mathrm{H}_{2} \mathrm{O}\right)_{2}(\mathrm{PPTTA})_{3 / 2}, \quad\right.$ PPTTA $=(1,4-$ phenylenebis(pyridine-4,2,6-triyl))tetrabenzoate, $S_{\mathrm{BET}}=4380$ $\left.\mathrm{m}^{2} \mathrm{~g}^{-1}\right)^{84}$ with storage capacity of $9.9 \mathrm{mmol} \mathrm{g}^{-1}(15.88 \mathrm{wt} \%)$ at $23{ }^{\circ} \mathrm{C}$ and 20 bar. Other MOFs, such as [Co(BDP)] (BDP $=1,4$ benzenedipyrazolate, $\left.S_{\mathrm{LANG}}=2911 \mathrm{~m}^{2} \mathrm{~g}^{-1}\right)^{85}$ and commercial product, Basolite A520 (aluminum fumarate, $S_{\mathrm{BET}}=1300 \mathrm{~m}^{2}$ $\left.\mathrm{g}^{-1}\right)^{86}$ have also shown promise as methane sorbents with methane storage capacity of $6.5 \mathrm{mmol} \mathrm{g}^{-1}(10.43 \mathrm{wt} \%)$ at $25{ }^{\circ} \mathrm{C}$ and $20 \mathrm{bar}$ and $3.80 \mathrm{mmol} \mathrm{g}^{-1}(6.10 \mathrm{wt} \%)$ at room temperature and pressure 20 bar, respectively.

\section{Conclusion}

The present study dealt with the preparation, characterisation and application of two novel aMOF compounds as adsorbents of greenhouse gases, carbon dioxide and methane. In the first phase, the extended nitrogen-rich tetraazo-tetracarboxylic acid, $\mathrm{H}_{4}$ MTB was prepared by a seven-step organic synthesis. Spectroscopic and NMR measurements confirmed its successful preparation. The next step was the preparation of aMOF compounds in combination with $\mathrm{H}_{4} \mathrm{MTB}$ and zinc(II) or cadmium(II) cations under the formation of as-synthesized materials, UPJS-13 (AS) and UPJS-14 (AS). In order to facilitate the activation of the compounds, the solvent molecules located in the cavities of the as-synthesized materials were exchanged with ethanol (UPJS-13 (EX) and UPJS-14 (EX)). Another variant of the compounds was prepared by a freeze-drying process using benzene (UPJS-13 (FD) and UPJS-14 (FD)). The compounds were characterised by elemental analysis, ICP-MS, infrared spectroscopy, solid-state NMR spectroscopy and PXRD. All prepared aMOFs were studied by nitrogen adsorption to find the best activation conditions. The compounds showed the highest surface areas after the freeze-drying process and at an activation temperature of $80{ }^{\circ} \mathrm{C}\left(S_{\text {BET }}=830 \mathrm{~m}^{2} \mathrm{~g}^{-1}\right.$ for UPJS-13 (EX) and $S_{\mathrm{BET}}=1057 \mathrm{~m}^{2} \mathrm{~g}^{-1}$ for UPJS-14 (EX)). aMOF materials were subsequently tested as greenhouse gases adsorbents, carbon dioxide and methane, by high-pressure adsorption measurements at $30{ }^{\circ} \mathrm{C}$ and pressure up to 20 bar. The maximal gas storage capacities were $30.01 \mathrm{wt} \%$ for UPJS-13 FD, $24.56 \mathrm{wt} \%$ for UPJS-14 FD of $\mathrm{CO}_{2}$ and $4.84 \mathrm{wt} \%$ for UPJS-13 FD and $6.38 \mathrm{wt} \%$ for UPJS-14 FD of $\mathrm{CH}_{4}$ at $30{ }^{\circ} \mathrm{C}$ and 20 bar. The increased adsorption capacity of carbon dioxide can be explained by the interaction of $\mathrm{CO}_{2}$ molecules with azo groups located in the structure of MTA ligand, or by interaction with CUSs. And the increased adsorption capacity of methane can be explained by the suitable pore size of the prepared materials.

\section{Author contributions}

Miroslav Almáši - conceptualization, data curation, formal analysis, investigation, supervision, validation, visualization, writing - original draft; writing - review \& editing, Nikolas Király - data curation, formal analysis, investigation, validation, visualization, writing - original draft; writing - review \& editing, 
Vladimír Zeleňák - funding acquisition, investigation, validation, Mária Vilková - data curation, formal analysis, investigation, validation, Sandrine Bourrelly - data curation, investigation, validation.

\section{Conflicts of interest}

No potential conflict of interest was reported by the authors.

\section{Acknowledgements}

This work was supported by the Scientific Grant Agency of the Slovak Republic (VEGA) project no. 1/0865/21 and from P. J. Safarik University project no. VVGS-2020-1667.

\section{References}

1 Q. Qian, P. A. Asinger, M. J. Lee, G. Han, K. Mizrahi Rodriguez, S. Lin, F. M. Benedetti, A. X. Wu, W. S. Chi and Z. P. Smith, Chem. Rev., 2020, 120, 8161-8266.

2 M. Fakhraei Ghazvini, M. Vahedi, S. Najafi Nobar and F. Sabouri, J. Environ. Chem. Eng., 2021, 9, 104790.

3 T. A. Goetjen, J. Liu, Y. Wu, J. Sui, X. Zhang, J. T. Hupp and O. K. Farha, Chem. Commun., 2020, 56, 10409-10418.

4 H. Konnerth, B. M. Matsagar, S. S. Chen, M. H. G. Prechtl, F.-K. Shieh and K. C.-W. Wu, Coord. Chem. Rev., 2020, 416, 213319.

5 J. Cao, X. Li and H. Tian, Curr. Med. Chem., 2020, 27, 59495969.

6 Y. Wang, J. Yan, N. Wen, H. Xiong, S. Cai, Q. He, Y. Hu, D. Peng, Z. Liu and Y. Liu, Biomaterials, 2020, 230, 119619.

7 S. Kim, K. Son and H. Oh, Korean J. Mater. Res., 2020, 30, 136141.

8 V. Zeleňák, M. Almáši, A. Zeleňáková, P. Hrubovčák, R. Tarasenko, S. Bourelly and P. Llewellyn, Sci. Rep., 2019, 9, 15572.

9 L. Wang, Sens. Actuators, A, 2020, 307, 111984.

10 H.-Y. Li, S.-N. Zhao, S.-Q. Zang and J. Li, Chem. Soc. Rev., 2020, 49, 6364-6401.

11 D. Capková, M. Almáši, T. Kazda, O. Čech, N. Király, P. Čudek, A. S. Fedorková and V. Hornebecq, Electrochim. Acta, 2020, 354, 136640.

12 J. Cai, Y. Song, X. Chen, Z. Sun, Y. Yi, J. Sun and Q. Zhang, J. Mater. Chem. A, 2020, 8, 1757-1766.

13 T. D. Bennett and S. Horike, Nat. Rev. Mater., 2018, 3, 431440.

14 H. Ohtsu, T. D. Bennett, T. Kojima, D. A. Keen, Y. Niwa and M. Kawano, Chem. Commun., 2017, 53, 7060-7063.

15 A. Halder and D. Ghoshal, CrystEngComm, 2018, 20, 13221345.

16 J. Fonseca, T. Gong, L. Jiao and H. L. Jiang, J. Mater. Chem. A, 2021, 9, 10562-10611.

17 Z. Hu, J. Lin, N. Ogiwara, A. Rodriguez, Y. Peng, Y. Wang, S. Horike and D. Zhao, CrystEngComm, 2016, 18, 2803-2807.

18 T. Zhang, J. Wang, W. Zhang, C. Yang, L. Zhang, W. Zhu, J. Sun, G. Li, T. Li and J. Wang, J. Mater. Chem. A, 2019, 7, 2845-2854.
19 R. Z. Zhang, S. Quan, M. Xia, Q. Wang, W. Zhang and J. M. Yang, J. Colloid Interface Sci., 2018, 525, 54-61.

20 M. Marmier, M. D. Wise, J. J. Holstein, P. Pattison, K. Schenk, E. Solari, R. Scopelliti and K. Severin, Inorg. Chem., 2016, 55, 4006-4015.

21 J. Fonseca and S. Choi, Microporous Mesoporous Mater., 2021, 310, 1-10.

22 J. Fonseca and S. Choi, Dalton Trans., 2021, 50, 3145-3154.

23 J. Fonseca and S. Choi, Catal.: Sci. Technol., 2020, 10, 82658282.

24 T. D. Bennett and A. K. Cheetham, Acc. Chem. Res., 2014, 47, 1555-1562.

25 X. Zhang, H. Li, X. Lv, J. Xu, Y. Wang, C. He, N. Liu, Y. Yang and Y. Wang, Chem.-Eur. J., 2018, 24, 8822-8832.

26 P. Ma, F. Meng, N. Wang, J. Zhang, J. Xie and B. Dai, ChemistrySelect, 2018, 3, 10694-10700.

27 B. Li and H. C. Zeng, Chem. Mater., 2019, 31, 5320-5330.

28 H. Zhou, M. Zheng, H. Tang, B. Xu, Y. Tang and H. Pang, Small, 2019, 16, 1904252.

29 C. Orellana-Tavra, E. F. Baxter, T. Tian, T. D. Bennett, N. K. Slater, A. K. Cheetham and D. Fairen-Jimenez, Chem. Commun., 2015, 51, 13878-13881.

30 X. Wu, H. Yue, Y. Zhang, X. Gao, X. Li, L. Wang, Y. Cao, M. Hou, H. An, L. Zhang, S. Li, J. Ma, H. Lin, Y. Fu, H. Gu, W. Lou, W. Wei, R. N. Zare and J. Ge, Nat. Commun., 2019, 10, 5165.

31 K. Suresh and A. J. Matzger, Angew. Chem., Int. Ed., 2019, 58, 16790-16794.

32 Y. Liu, S. Lv, D. Liu and F. Song, Acta Biomater., 2020, 116, 16-31.

33 C. Orellana-Tavra, M. Köppen, A. Li, N. Stock and D. FairenJimenez, ACS Appl. Mater. Interfaces, 2020, 12, 5633-5641.

34 F. Yang, W. Li and B. Tang, J. Alloys Compd., 2018, 733, 8-14. 35 W. Niu and Y. Yang, ACS Appl. Energy Mater., 2018, 1, 24402445.

36 J.-W. Xiu, G.-E. Wang, M.-S. Yao, C.-C. Yang, C.-H. Lin and G. Xu, Chem. Commun., 2017, 53, 2479-2482.

37 T. D. Bennett, P. J. Saines, D. A. Keen, J.-C. Tan and A. K. Cheetham, Chem.-Eur. J., 2013, 19, 7049-7055.

38 T. Zhang, J. Wang, W. Zhang, C. Yang, L. Zhang, W. Zhu, J. Sun, G. Li, T. Li and J. Wang, J. Mater. Chem. A, 2019, 7, 2845-2854.

$39 \mathrm{H}$. Zhang, Ice templating and freeze-drying for porous materials and their applications, Wiley-VCH, Weinheim, Germany, 2018.

40 L. Ma, A. Jin, Z. Xie and W. Lin, Angew. Chem., Int. Ed., 2009, 48, 9905-9908.

41 https://ec.europa.eu/clima/policies/strategies/progress_en, Climate Action - European Commission, 2017.

42 E. J. Kim, R. L. Siegelman, H. Z. Jiang, A. C. Forse, J.-H. Lee, J. D. Martell, P. J. Milner, J. M. Falkowski, J. B. Neaton, J. A. Reimer, S. C. Weston and J. R. Long, Science, 2020, 369, 392-396.

43 V. Zeleňák, M. Skřínska, F. R. Siperstein and A. Patti, Appl. Surf. Sci., 2019, 476, 886-896.

44 J.-T. Anyanwu, Y. Wang and R. T. Yang, Ind. Eng. Chem. Res., 2019, 59, 7072-7079. 
45 P. Zhao, G. Zhang and L. Hao, Adsorption, 2020, 26, 749-764. 46 M. Almáši, V. Zeleňák, A. Zukal, J. Kuchár and J. Čejka, Dalton Trans., 2016, 45, 1233-1242.

47 C. Klumpen, M. Breunig, T. Homburg, N. Stock and J. Senker, Chem. Mater., 2016, 28, 5461-5470.

48 S. Shukla, A. Mahata, B. Pathak and B. Lochab, RSC Adv., 2015, 5, 78071-78080.

49 J. Gonda, S. Fazekašová, M. Martinková, T. Mitríková, D. Roman and M. B. Pilátová, Org. Biomol. Chem., 2019, 17, 3361-3373.

50 A. D. Wiersum, C. Giovannangeli, D. Vincent, E. Bloch, H. Reinsch, N. Stock, J. S. Lee, J.-S. Chang and P. L. Llewellyn, ACS Comb. Sci., 2013, 15, 111-119.

51 E. W. Lemmon and H. M. McLinden, MO reference fluid thermodynamic and transport properties; REFPROP 8.0, National Institute of Standards and Technology, Gaithersburg MD 2007.

52 Y. Xu, P. M. J. Szell, V. Kumar and D. L. Bryce, Coord. Chem. Rev., 2020, 411, 213237.

53 S. Naoki, N. Akira and K. Keisaku, Bull. Chem. Soc. Jpn., 1995, 68, 2151-2157.

54 B. H. Meier, F. Graf and R. R. Ernst, J. Chem. Phys., 1982, 76, 767.

55 F. Gul-E-Noor, B. Jee, A. Poppl, M. Hartmann, D. Himsl and M. Bertmer, Phys. Chem. Chem. Phys., 2011, 13, 7783-7788.

56 J. Tang, S. Li, Y. Chu, Y. Xiao, J. Xu and F. Deng, J. Phys. Chem. C, 2019, 123, 24062-24070.

57 V. Martins, J. Xu, X. Wang, K. Chen, I. Hung, Z. Gan, C. Gervais, C. Bonhomme, S. Jiang, A. Zheng, B. E. G. Lucier and Y. Huang, J. Am. Chem. Soc., 2020, 142, 14877-14889.

58 H. C. Hoffmann, M. Debowski, P. Müller, S. Paasch, I. Senkovska, S. Kaskel and E. Brunner, Materials, 2012, 5, 2537-2572.

59 M. Almáši, V. Zeleňák, R. Gyepes, Ľ. Zauška and S. Bourrelly, RSC Adv., 2020, 10, 32323-32334.

60 Y. E. Cheon and M. P. Suh, Chem. Commun., 2009, 2296.

61 M. Almáši, V. Zeleňák, M. Opanasenko and J. Čejka, Dalton Trans., 2014, 43, 3730.

62 L. Wen, P. Cheng and W. Lin, Chem. Commun., 2012, 48, 2846.

63 M. Zhang, Y.-P. Chen, M. Bosch, T. Gentle, K. Wang, D. Feng, Z. U. Wang and H.-C. Zhou, Angew. Chem., Int. Ed., 2013, 53, 815-818.

64 Y. Wang, Q. Liu, Q. Zhang, B. Peng and H. Deng, Angew. Chem., Int. Ed., 2018, 57, 7120-7125.

65 P. Das and S. K. Mandal, ACS Appl. Mater. Interfaces, 2020, 12, 37137-37146.

66 A. Mukhtar, S. Ullah, A. Inayat, S. Saqib, N. B. Mellon, M. A. Assiri, A. G. Al-Sehemi, M. B. Khan Niazi, Z. Jahan, M. A. Bustam and M. Ibrahim, Energy, 2021, 216, 119230.
67 R. Zhang, D.-X. Meng, F.-Y. Ge, J.-H. Huang, L.-F. Wang, Y.-K. Xv, X.-G. Liu, M.-M. Meng, H. Yan, Z.-Z. Lu, H.-G. Zheng and W. Huang, Dalton Trans., 2020, 49, 21452150.

68 S. S. Dhankhar and C. M. Nagaraja, New J. Chem., 2020, 44, 9090-9096.

69 W. R. Webb, M. E. Potter, D. J. Stewart, S. J. Elliott, P. J. Sazio, Z. Zhang, H. K. Luo, J. Teng, L. Zhang, C. Ivaldi, I. Miletto, E. Gianotti and R. Raja, Chem.-Eur. J., 2020, 26, 1360613610.

70 L. Wang, L. Yang, L. Gong, R. Krishna, Z. Gao, Y. Tao, W. Yin, Z. Xu and F. Luo, Chem. Eng. J., 2020, 383, 123117.

71 S. Salehi, M. Anbia and F. Razavi, Environ. Prog. Sustainable Energy, 2019, 39, 13302.

72 H. A. Patel, S. Hyun Je, J. Park, D. P. Chen, Y. Jung, C. T. Yavuz and A. Coskun, Nat. Commun., 2013, 4, 1357.

73 Ü. Kökçam-Demir, A. Goldman, L. Esrafili, M. Gharib, A. Morsali, O. Weingart and C. Janiak, Chem. Soc. Rev., 2020, 49, 2751-2798.

74 H. Chun, D. Kim, D. N. Dybtsev and K. Kim, Angew. Chem., Int. Ed., 2004, 43, 971-974.

75 M. Almáši, V. Zeleňák, R. Gyepes, S. Bourrelly, M. V. Opanasenko, P. L. Llewellyn and J. Čejka, Inorg. Chem., 2018, 57, 1774-1786.

76 M. Almáši, V. Zeleňák, M. V. Opanasenko and J. Čejka, Catal. Lett., 2018, 148, 2263-2273.

77 L. Li, S. Tang, C. Wang, X. Lv, M. Jiang, H. Wu and X. Zhao, Chem. Commun., 2014, 50, 2304.

78 J. Luo, J. Wang, G. Li, Q. Huo and Y. Liu, Chem. Commun., 2013, 49, 11433.

79 J. Kim, Y.-R. Lee and W.-S. Ahn, Chem. Commun., 2013, 49, 7647.

80 N. C. Burtch, H. Jasuja, D. Dubbeldam and K. S. Walton, J. Am. Chem. Soc., 2013, 135, 7172-7180.

81 J. Alcañiz-Monge, M. A. De La Casa-Lillo, D. Cazorla-Amorós and A. Linares-Solano, Carbon, 1997, 35, 291-297.

82 R. B. Getman, Y.-S. Bae, C. E. Wilmer and R. Q. Snurr, Chem. Rev., 2011, 112, 703-723.

83 B. Wang, X. Zhang, H. Huang, Z. Zhang, T. Yildirim, W. Zhou, S. Xiang and B. Chen, Nano Res., 2020, 14, 507-511.

84 Y. Peng, V. Krungleviciute, I. Eryazici, J. T. Hupp, O. K. Farha and T. Yildirim, J. Am. Chem. Soc., 2013, 135, 11887-11894.

85 J. A. Mason, J. Oktawiec, M. K. Taylor, M. R. Hudson, J. Rodriguez, J. E. Bachman, M. I. Gonzalez, A. Cervellino, A. Guagliardi, C. M. Brown, P. L. Llewellyn, N. Masciocchi and J. R. Long, Nature, 2015, 527, 357-361.

86 M. Gaab, N. Trukhan, S. Maurer, R. Gummaraju and U. Müller, Microporous Mesoporous Mater., 2012, 157, 131136. 